\title{
IS EMOTIONAL INTELLIGENCE WORTHWHILE? ASSESSING INCREMENTAL VALIDITY AND ADVERSE IMPACT
}

\author{
A Thesis \\ by \\ DANA LANAY RHODES
}

\begin{abstract}
Submitted to the Office of Graduate Studies of
Texas A\&M University

in partial fulfillment of the requirements for the degree of

MASTER OF SCIENCE
\end{abstract}

August 2008

Major Subject: Psychology 


\title{
IS EMOTIONAL INTELLIGENCE WORTHWHILE? ASSESSING INCREMENTAL VALIDITY AND ADVERSE IMPACT
}

\author{
A Thesis \\ by
}

\section{DANA LANAY RHODES}

\author{
Submitted to the Office of Graduate Studies of \\ Texas A\&M University \\ in partial fulfillment of the requirements for the degree of \\ MASTER OF SCIENCE
}

Approved by:

Chair of Committee, Daniel A. Newman

Committee Members, Winfred Arthur, Jr.

Murray R. Barrick

Gerianne M. Alexander

Head of Department, Leslie C. Morey

August 2008

Major Subject: Psychology 


\author{
ABSTRACT \\ Is Emotional Intelligence Worthwhile? Assessing Incremental Validity and Adverse \\ Impact. (August 2008) \\ Dana Lanay Rhodes, B.A., University of Southern California \\ Chair of Advisory Committee: Dr. Daniel A. Newman
}

Emotional intelligence is defined as the ability to perceive emotion, understand emotion, facilitate thought with emotion, and regulate emotion. Considerable debate exists as to whether emotional intelligence adds incremental validity above more wellknown predictors of performance, namely the Big Five personality traits and cognitive ability. Furthermore, no theory directly specifies the roles of separate emotional intelligence (EI) dimensions in relationship to job performance. This paper offers several contributions: (a) a summary of theoretical links between EI and job performance, (b) meta-analytic incremental validity estimation for two different conceptualizations of emotional intelligence - labeled ability EI and mixed EI - over and above cognitive ability and Big Five personality composites, (c) estimation of Black-White and femalemale adverse impact attributable to the use of EI for selection purposes, and (d) a theoretical model of EI subdimensions, demonstrating that emotion regulation mediates the effects of emotion perception and emotion understanding on job performance, and that emotional competencies serve as partial mechanisms for the effects of Conscientiousness and cognitive ability on performance. 
TABLE OF CONTENTS

Page

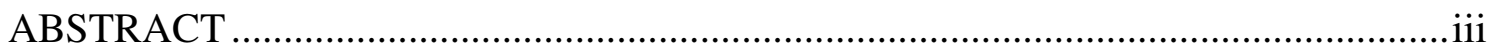

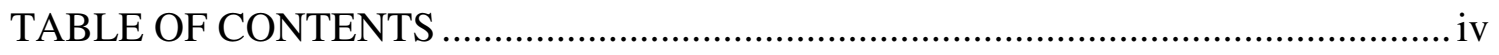

LIST OF FIGURES ...................................................................................... vi

LIST OF TABLES ….................................................................................... vii

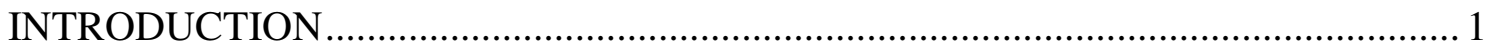

Ability vs. Mixed Models of Emotional Intelligence....................................... 2

A Construct-Method Distinction .............................................................. 5

The Emotional Intelligence Concept and its Relationship with Job

Performance: The Cascading Model of Emotional Intelligence ......................... 7

Perceiving Emotions and Job Performance........................................... 9

Understanding Emotions and Job Performance .................................. 11

Emotion Facilitation and Job Performance ......................................... 13

Managing/Regulating Emotions and Job Performance ......................... 14

The Cascading Model of EI, Personality, and Cognitive Ability....................... 16

Incremental Validity of Emotional Intelligence................................................ 19

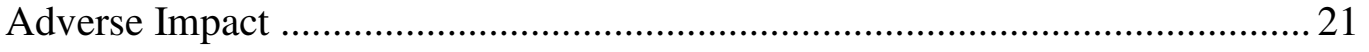

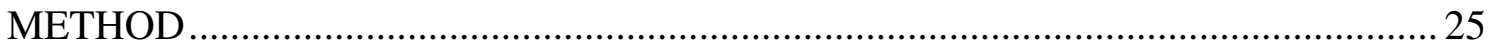

Published Effect Sizes ............................................................................... 25

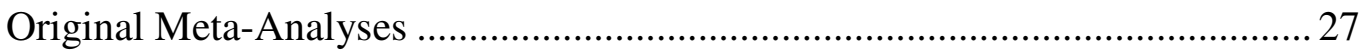

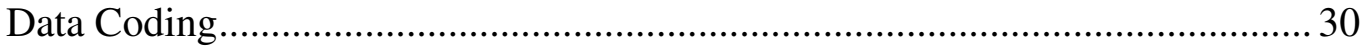

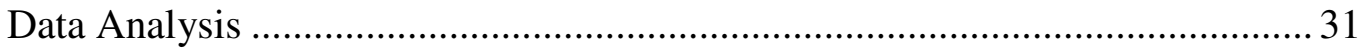

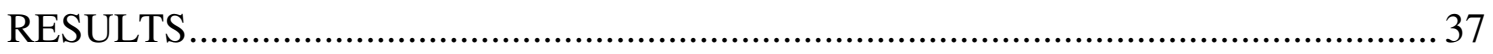

Meta-Analytic Estimates ....................................................................... 37

Emotional Intelligence and Big Five Personality Trait Meta-Analytic

Estimates ................................................................................... 37

Emotional Intelligence and Cognitive Ability Meta-Analytic Estimates.42

Emotional Intelligence and Job Performance Meta-Analytic Estimates. 43

Results of Hypothesis Tests ...................................................................... 44

DISCUSSION AND CONCLUSIONS ................................................................. 50 
Page

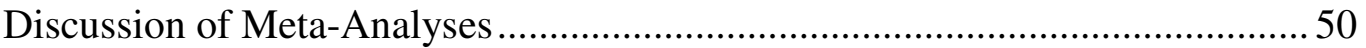

Strengths and Limitations............................................................................. 55

Directions for Future Research...................................................................... 58

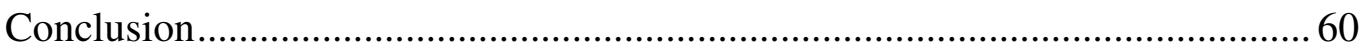

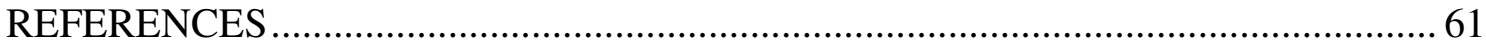

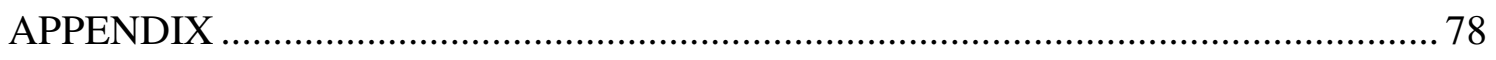

VITA 


\section{LIST OF FIGURES}

FIGURE

Page

1 Mediated model of emotional intelligence dimensions and job performance....... 9

2 Mediated model of emotional intelligence dimensions and job performance

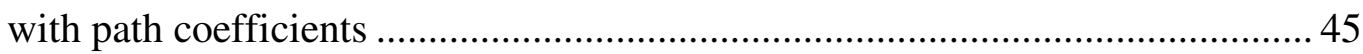




\section{LIST OF TABLES}

TABLE

Page

1 Classification of Common EI Measures with Four Construct-Method Pairings .. 6

2 Definitions of EI Dimensions, as Described by Mayer and Salovey (1997) ...... 8

3 Meta-Analytic Correlation Matrix of Previous Meta-Analytic Estimates .......... 26

4 Meta-Analytic Correlation Matrix of MEIS/MSCEIT, Job Performance, Personality, Cognitive Ability, Race, and Sex .............................................. 33

5 Meta-Analytic Correlation Matrix of Performance-Based Ability EI, SelfReport Ability EI, Self-Report Mixed EI, Job Performance, Personality, and Cognitive Ability ................................................................................. 35

6 Estimates of Female-Male and Black-White Subgroup d ................................ 36

7 Meta-Analytic Correlation Matrix of Emotional Intelligence, Job Performance, Personality, and Cognitive Ability............................................ 38

8 Meta-Analytic Results for Emotional Intelligence and Its Dimensions with Personality Traits, Cognitive Ability, and Job Performance.............................. 39

9 Meta-Analytic Results for Construct-Method Pairings of Emotional Intelligence, Big Five Personality Traits, Cognitive Ability, and Job Performance

10 Incremental Validity and Adverse Impact Reduction for Emotional Intelligence Construct-Method Pairings 46 


\section{INTRODUCTION}

Emotional intelligence (EI) is a set of abstract concepts connected to various definitions and operations, which have garnered criticism as "poorly defined and poorly measured" (Murphy, 2006, p. 346). Much of the hype over EI has been fueled by Goleman's (1995) bestselling book, Emotional Intelligence: Why It Can Matter More Than IQ, in which Goleman claimed that EI is as powerful, and at times more powerful [has higher predictive validity], than IQ. Specifically, he claimed that the unique contribution of emotional intelligence to effective performance at work is as much as 66 percent for all jobs and 85 percent for leadership jobs (1995).

The current study builds upon the meta-analytic research of Van Rooy and colleagues $(2004,2005)$ to assess the empirical merit of Goleman's (1995) claim that emotional intelligence is a construct unique from more established constructs. We offer several contributions: (a) a summary of theoretical links between EI and job performance, (b) incremental validity estimation for two different conceptualizations of emotional intelligence-labeled ability EI and mixed EI-over and above cognitive ability and Big Five personality composites, (c) estimation of Black-White and femalemale adverse impact attributable to the use of EI for selection purposes, and (d) a theoretical mediated model of EI subdimensions. Of the various construct-method pairings commonly used in EI research, we show that only self-reports of mixed EI offer considerable incremental validity over a composite of Big Five personality traits and

This thesis follows the style and format of the Journal of Applied Psychology. 
cognitive ability. In addition, these self-report measures based on mixed EI decrease the potential for adverse impact in selection when added to cognitive ability. In contrast, self-report and performance-based (e.g., multiple-choice) measures based on ability EI offer considerably less incremental validity over Big Five personality traits and cognitive ability than self-report mixed measures of EI, although these measures do offer potential reduction in adverse impact when compared to measures of cognitive ability. Thus, we show that some EI inventories hold the potential to reduce adverse impact while preserving the average predicted performance of new hires, while others may not only reduce adverse impact, but may also increase prediction of job performance. Coincident with our presentation of these empirical results, we echo earlier work (Landy, 2005; Matthews, Zeidner, \& Roberts, 2002; Mayer, 1999; Sternberg, 2002) highlighting the dire need to assess and advance the construct validity of EI prior to the widespread application of EI measures, and propose a theoretical elaboration of the roles of EI dimensions in determining job performance. In short, we employ both performance and diversity criteria, seeking to answer the question, "Is emotional intelligence worthwhile?"

Ability vs. Mixed Models of Emotional Intelligence

Currently there are two popular construct models available to define emotional intelligence: (a) an ability model, and (b) a mixed (traits with abilities) model (Mayer, Salovey, \& Caruso, 2000). Ability models, originally conceptualized by Mayer et al. (2000), posit that emotional intelligence is a type of intelligence or aptitude, and therefore should overlap with cognitive ability. Formally defined, ability models 
conceptualize emotional intelligence as "the ability to perceive accurately, appraise, and express emotion; the ability to access and/or generate feelings when they facilitate thought; the ability to understand emotion and emotional knowledge; and the ability to regulate emotions to promote emotional and intellectual growth" (Mayer \& Salovey, 1997, p. 10).

In contrast to ability models, mixed EI models do not classify EI as an intelligence, but rather as a combination of intellect and various measures of personality and affect (typically measured via self-report; Petrides \& Furnham, 2001). Mixed models have been postulated to have a strong personality component that differs from ability models (Petrides \& Furnham, 2001) — and although many of the underlying premises between the two models are quite similar (Ciarrochi, Chan, \& Caputi, 2000) empirical evidence suggests "they [ability and mixed EI models] diverge more than they converge $\left(\hat{\rho}_{\text {ability, mixed }}=.24\right)$, indicating that two different constructs are being tapped," (Van Rooy et al., 2005, p. 453). Specifically, mixed models of EI occupy a considerably larger construct space than ability models of EI, for which mixed models have been criticized (Matthews et al., 2002). For example, mixed models have been formally defined as "an array of noncognitive capabilities, competencies, and skills that influence one's ability to succeed in coping with environmental demands and pressures" (Bar-On, 1997, p. 14). This particular conceptualization of EI provided by Bar-On (1997) involves five dimensions, including Intrapersonal Skills, Interpersonal Skills, Adaptability, Stress-Management, and General Mood. Intrapersonal Skills, according to Bar-On's (1997) mixed model, involve self-regard, emotional self-awareness, assertiveness, 
independence, and self-actualization. The dimension of Interpersonal Skills is comprised of empathy, social responsibility, and interpersonal relationship skills. Meanwhile, Stress Management involves both stress tolerance and impulse control, and the dimension of Adaptability consists of reality-testing, flexibility, and problem-solving. Finally, the dimension of General Mood involves optimism and happiness. Clearly, this model includes a broad array of intellect (e.g., problem-solving), personality (e.g., assertiveness), and affect (e.g., stress tolerance) that characterizes it as a mixed model. Goleman (1995) offers an equally expansive conceptualization of emotional intelligence that has also been classified as a mixed model (Mayer et al. 2000): "there is an oldfashioned word for the body of skills that emotional intelligence represents: character" (p. 28). Critics have pointed out that Goleman's (1995) work appears to define EI by exclusion as any desirable characteristic not represented by cognitive ability (Zeidner, Matthews, \& Roberts, 2004). Given these all-encompassing definitions of emotional intelligence, it is not surprising that critics have labeled emotional intelligence as poorly defined (Murphy, 2006). Specifically, critics assert that these overly-broad conceptualizations of EI are too redundant with personality traits to justify a distinct construct (Daus \& Ashkanasy, 2003). For example, Conte and Dean (2006) note, "nearly all self-report EI scales relate to well-established personality dimensions such as Neuroticism and Extraversion," (p. 68). In addition, critics of mixed EI models have noted that these models are the primary contributor to the recent "bandwagon effect" of EI (Daus, 2006, p. 301). That is, EI has experienced a recent fadification in organizations, primarily due to Goleman's mixed model of EI that was originally 
presented in his wildly popular book, Emotional Intelligence: Why it May Matter More than IQ (1995). Unfortunately, because mixed EI models have failed to meet standards of scientific discourse in the midst of widespread application in organizations, some have re-labeled the "bandwagon effect" as the "broken oxcart phenomenon" (Daus, 2006, p. 302). In other words, while many consultants and organizations remain on the proverbial EI bandwagon, this bandwagon has yet to meet many of the standards of scientific research, and thus resembles more of a stagnant, broken oxcart than a forwardmoving bandwagon. As a result, critics have contended that only the ability EI models are worth studying (Daus \& Ashkanasy, 2005), or at least that mixed models are profoundly flawed (through lack of empirical bases and overly broad conceptualization; Murphy, 2006).

Some critics have painted an even more dismal picture for EI. These scholars have proposed that all conceptualizations of EI (both ability and mixed) are likely to reflect mere combinations of well-known and established constructs (Eysenck, 1998; Landy, 2005; Locke, 2005; Raad, 2005). In regard to the current discussion, we seek to investigate empirically whether ability and mixed models of EI are in fact redundant with previously established constructs in their prediction of job performance. We concurrently provide an integrated theoretical model of the interrelationships among cognitive ability, personality, and subfacets of EI.

\section{A Construct-Method Distinction}

Before we review the conceptual definitions of four EI dimensions and propose theoretical linkages between EI competencies and job performance, we point out an 
important distinction relevant to EI research: the distinction between constructs and measurement methods. A depiction of EI constructs and methods is shown in Table 1.

Table 1

Classification of Common EI Measures with Four Construct-Method Pairings

\begin{tabular}{|l|l|l|}
\hline \multirow{2}{*}{ Method } & \multicolumn{2}{|c|}{ Construct } \\
\hline \multirow{2}{*}{ Self-report } & \multicolumn{1}{|c|}{ Ability-based EI } & \multicolumn{1}{c|}{ Mixed-based EI } \\
& Self-report Ability Measures: & Self-report Mixed Measures: \\
& EIS & ECI \\
& TEIQue & EQ-i \\
& WEIP & TMMS \\
& WLEIS & SUEIT \\
\hline \multirow{2}{*}{ Performance-based } & Performance-based Ability & Performance-based Mixed \\
& Measures: & Measures: \\
& MEIS & (no current measures) \\
& MSCEIT & \\
\hline
\end{tabular}

Note. EIS: Emotional Intelligence Scale (Schutte et al., 1998); TEIQue: Trait Emotional Intelligence Questionnaire (Petrides \& Furnham, 2003); WEIP: Workgroup Emotional Intelligence Profile (Jordan, Ashkanasy, Hartel, \& Hooper, 2002) ; WLEIS: Wong and Law Emotional Intelligence Scale (Wong \& Law, 2002); ECI: Emotional Competence Inventory (Sala, 2002); EQ-i: Emotional Quotient Inventory (Bar-On, 1997); TMMS: Trait Meta Mood Scale (Salovey, Mayer, Goldman, Turvey, \& Palfai, 1995); SUIET: Swinburne University Emotional Intelligence Test (Palmer \& Stough, 2001); MEIS: Multifactor Emotional Intelligence Scale (Mayer, Salovey, \& Caruso, 1999); MSCEIT: Mayer - Salovey - Caruso Emotional Intelligence Test (Mayer, Salovey, Caruso, \& Sitarenios, 2003).

As originally developed by Mayer et al. (2000), the ability model of EI may be indexed with either performance-based measures (e.g., multiple-choice tests) or selfreport measures, while the mixed model of EI is typically only measured through selfreport. In contrast, Zeidner et al. (2004) suggest that operationalizations of ability models employ only performance-based measures, and self-report measures of EI are used to operationalize only mixed models (also see Petrides \& Furnham, 2001). This categorization of ability models as performance-based measures and mixed models as self-report measures represents a tendency for recent EI literature to confound the 
construct (i.e., ability model vs. mixed model) with the method (i.e., performance-based measure vs. self-report measure). This confound, which has been called "the predictor construct - predictor method distinction" (Arthur \& Villado, 2008, p. 435), has resulted in the potential for several self-report measures of EI, including Jordan et al.'s measure of workgroup EI (WEIP; 2002), Schutte et al.'s EI scale (EIS; 1998), Petrides and Furnham's self-report measure of EI (TEIQue; 2003), and the Wong and Law Scale of Emotional Intelligence (WLEIS; Wong \& Law, 2002) to be miscategorized as mixed (due to their self-report nature), even though these measures are based on ability models. For a specific example, Schutte et al.'s self-report EI scale (1998) is based on the ability model, but has been classified as mixed due to its self-report format (cf. Spector, \& Johnson, 2006; Van Rooy et al., 2005). Regarding the current discussion, it is important to clarify the construct-method confusion in the EI literature in order to investigate the relationships between EI and the existing personality and ability constructs. Specifically, we seek to examine how the relationship between EI and existing constructs differs with the EI construct measured (ability vs. mixed) and method used to measure this construct (self-report vs. performance-based).

The Emotional Intelligence Concept and its Relationship with Job Performance: The Cascading Model of Emotional Intelligence

Due to the lack of scientific rigor often associated with mixed models of EI, the current paper develops theoretical linkages between EI and job performance by utilizing the ability model, which has been labeled "the appropriate horse to drive the emotional intelligence cart" (Daus, 2006, p. 305). According to the ability model, EI can be broken 
down into four-dimensions: emotion perception, emotion understanding, emotion facilitation, and emotion regulation (Mayer \& Salovey, 1997). Definitions for each of these dimensions are presented in Table 2. In the following section, we flesh out the theoretical relationship between each of these dimensions and job performance, and we propose a cascading model of EI in which emotional competencies serve as partial mechanisms by which personality and cognitive ability affect job performance.

Table 2

Definitions of EI Dimensions, as Described by Mayer and Salovey (1997)

\begin{tabular}{|c|c|}
\hline Dimension of EI & Definition \\
\hline Emotion Perception & $\begin{array}{l}\text { The ability to: } \\
\text { - identify emotion in oneself } \\
\text { - identify emotion in others } \\
\text { - express emotion accurately }\end{array}$ \\
\hline Emotion Understanding & $\begin{array}{l}\text { The ability to: } \\
\text { - label emotions } \\
\text { - recognize relationships among emotions } \\
\text { - interpret the meaning of emotions } \\
\text { - understand complex feelings } \\
\text { - recognize transitions between emotions }\end{array}$ \\
\hline Emotion Facilitation & $\begin{array}{l}\text { The ability to: } \\
\text { - use emotion to prioritize thinking } \\
\text { - use emotions to aid judgment } \\
\text { - induce emotional states }\end{array}$ \\
\hline Emotion Regulation & $\begin{array}{l}\text { The ability to: } \\
\text { - engage or detach from emotion when necessary } \\
\text { - reflectively monitor emotions } \\
\text { - manage emotions }\end{array}$ \\
\hline
\end{tabular}

Specifically, in the cascading model of EI (Figure 1) we propose that three of the four dimensions of EI are related to job performance in a sequential fashion, such that emotion perception precedes emotion understanding, emotion understanding leads to emotion regulation, and emotion regulation is the key construct that subsequently affects job performance. In other words, in order for EI to affect job performance, an individual 
must first perceive emotions, then understand what these emotions are and how they can affect a given situation, which then imbues the individual with the ability to regulate these emotions. We note that the third dimension of EI, emotion facilitation, is not included in the cascading model of EI due to its conceptual redundancy with other dimensions and lack of empirical support (Gignac, 2005; Palmer, Gignac, Manocha, \& Stough, 2005; Rossen, Kranzler, \& Algina, 2008), which is developed further in the following section. The cascading model of EI is shown in Figure 1.

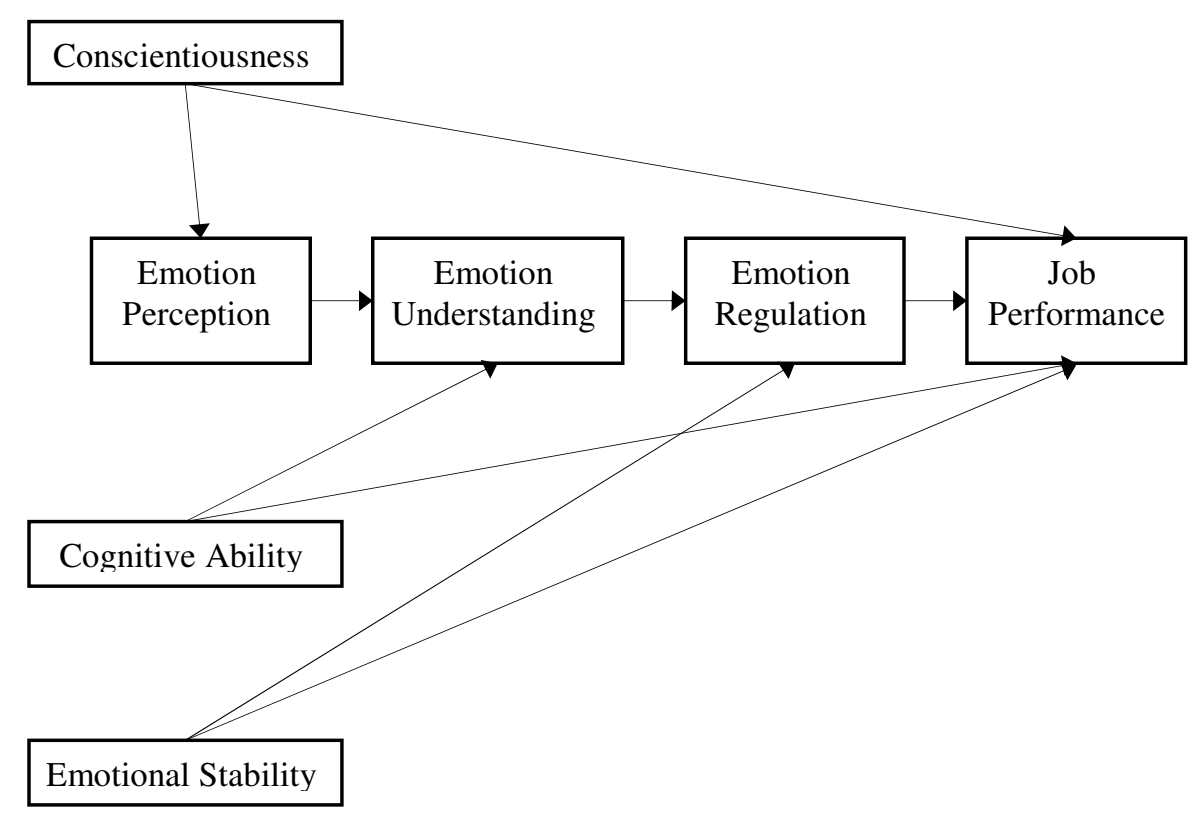

Figure 1. Mediated model of emotional intelligence dimensions and job performance. The dimension of emotion facilitation is explicitly excluded from the model for reasons described in the following section.

Perceiving Emotions and Job Performance. Mayer and Salovey's (1997) original concept of perceiving emotions includes not only perception of emotion, but appraisal and expression of emotion as well. Theoretically, the ability to perceive and appraise 
emotions in others may be related to job performance because it increases the amount of information transmitted in social contexts in the workplace. Subtle representations of emotion such as body language, voice inflection, and facial expressions are often present in communication, and individuals with an acute ability to perceive and appraise emotion are more apt to recognize such details. As a result, individuals who are able to perceive emotion through these signals are rewarded with a more complete picture of the information transferred in social contexts, thereby aiding communication. For example, a conversation between supervisor and subordinate involves information transfer on several levels, including both spoken words and unspoken cues such as mannerisms, voice inflection, and facial expressions. While most subordinates receive information spoken to them, only those with higher levels of perceiving emotion would notice unspoken bits of emotional information such as subtle voice inflection. The reception of unspoken emotional signals by perceivers has been said to allow effective communication in a social exchange (Owren, Rendall, \& Bachorowski, 2005). Thus, individuals with the highest levels of perceiving emotion are able to glean the most information from social contexts by drawing on subtle signals of emotion, which enhances communication and allows for subsequent decisions to be based on a more complete set of information.

In addition to the perception and appraisal of emotions in others, the perception and appraisal of emotion in oneself may also contribute to job performance. Seo, Barrett, and Bartunek (2004) have proposed that the basic elements of emotion, core affect, contribute to the decision making process by adding value to judgments that affect goal 
level, goal commitment, and behavioral outcomes. In this way, accurate perception and appraisal of emotion in the self acts as a heuristic to prioritize information and simplify the decision making process, which may then affect behavioral outcomes (Seo et al., 2004).

In sum, the perception of emotion increases the amount of information transferred in communication, allowing for subsequent decisions to be based on a more complete assessment of the situation. We propose that this is a necessary first step in the chain of events that causes EI to affect job performance. Specifically, an individual must perceive an emotion in order to utilize an existing knowledge-base to determine the appropriate response (i.e., understanding emotion) and subsequently respond (i.e., regulating emotion). This idea has been previously presented by George (2000), who has noted that "in order to be able to manage the moods and emotions of others, people must be able to appraise and express emotions" (p. 1038). This points to a fundamental causal structure underlying Mayer and Salovey's (1997) four-branch model; any conscious regulation of emotion requires that an individual first perceive the emotion. For example, a subordinate who needs to control his/her frustration in front of a supervisor must first recognize s/he is frustrated in order to begin the process of emotion regulation. Therefore, I propose the dimension of emotion perception is the first step by which EI comes to affect job performance, as illustrated in Figure 1.

Understanding Emotions and Job Performance. The second branch of EI involves understanding how emotions evolve over time, how emotions differ from each other, and which emotion is most appropriate for a given context (Mayer \& Salovey, 
1997). The cascading model of EI proposed here suggests that once an individual perceives emotion in the self or in others, this individual can subsequently use his/her understanding of emotions to guide his/her decision processes. Specifically, one's depth of understanding emotions consists of discerning which emotions should be regulated in any given context. Those with heightened levels of emotion understanding know when and where certain emotions are appropriate, and how a given emotion may influence decisions and the behavior of others. For instance, a leader who is surprised when his/her subordinates respond with anxiety to an announced restructuring lacks knowledge about the determinants of emotions (George, 2000). If this leader had a better understanding of emotion, s/he may choose a different place or manner to announce the information and prepare for anxious responses.

In the extreme, research has shown that individuals with brain damage to areas that involve processing the consequences of affective reactions tend to make catastrophic social decisions (Damasio, 1994). On the other end of the spectrum, individuals who do understand the consequences and appropriateness of emotion are able to use this to guide their decisions and regulate their own emotion. For example, research has shown that positive and negative moods have distinct processing advantages and disadvantages. People in positive moods invoke "creative, open, constructive, and inclusive thinking styles, use broader categories, show greater cognitive and behavioral flexibility, and perform well on secondary tasks" (Forgas, 2002, p. 5). However, people in positive moods also tend to make attribution errors more often (Forgas, 1998) and produce weaker arguments than individuals in negative moods (Forgas, Ciarrochi, \& Moylan, 
2000). Meanwhile, people in negative moods use a more analytical and cautious processing style (Fiedler, 2000) which has been shown to facilitate attention to detail and accurate appraisals (Sinclair 1988; Sinclair \& Mark, 1992). Therefore, an employee who is attempting to produce an innovative and creative ad campaign may be best suited for the task if s/he is in a positive mood, while an employee preparing to bargain or complete a performance appraisal would be better off in a negative mood. In sum, one's cognitive schema regarding which emotions are best suited for a given context represents a body of knowledge that varies in depth across individuals.

This dimension of emotion understanding occupies the second link in the cascading model of EI. In this position, emotion understanding serves as a mediator of the relationship between emotion perception and emotion regulation. That is, an accurate understanding of how to respond to an emotion is necessary in order for the perception of an emotion to result in effectual regulation of that emotion. In other words, without an understanding of which emotion is most appropriate (positive emotion, negative emotion, or otherwise) in a given situation, a person cannot effectively regulate emotion. This relationship is shown in Figure 1.

Emotion Facilitation and Job Performance. The third branch of EI, emotion facilitation, includes an ability to identify and focus one's own emotions on the task at hand, and subsequently use these emotions to facilitate thought (Mayer \& Salovey, 1997). According to Salovey and Mayer (1990), this can involve using emotions as motivation to perform, increase confidence, or think creatively. 
Unfortunately, empirical support for the existence of emotion facilitation as a distinct dimension of EI is lacking. Gignac (2005), Palmer et al. (2005), and Rossen et al. (2008) have all demonstrated the poor fit of EI factor-analytic models that include the dimension of emotion facilitation, and the superior fit of EI models in which this dimension is removed. Moreover, it is not theoretically clear how emotion facilitation differs from emotion regulation. For example, Salovey and Mayer (1990) posit that emotion facilitation involves using emotion in a variety of contexts to facilitate the attainment of goals. At the core of this goal attainment, using emotion must involve the induction of an emotion, such as inducing a positive or negative mood, which is conceptually redundant with regulating positive or negative moods. Because empirical research has shown a lack of construct validity for the dimension of emotion understanding, and the theoretical basis of a distinct dimension of emotion understanding is not entirely clear, the theoretical cascading model of EI does not include this aspect of EI.

Managing/Regulating Emotions and Job Performance. Finally, the fourth branch of emotional intelligence incorporates the ability to manage and control one's own emotions (i.e., emotion regulation, see Larsen, 2000; and Grandey, 2003), along with the capability to influence others' emotional states (Mayer \& Salovey, 1997) — characteristics believed to be valuable in achieving intended goals in the workplace (Salovey \& Grewal, 2005). In regard to the cascading model of EI proposed here, emotion regulation serves as the key element by which EI affects job performance. Although emotion perception and emotion understanding are necessary preconditions for 
the regulation of emotion to occur, actual emotion regulation involves inducing a particular mood in hope of attaining a goal state, which can serve a variety of functions in aiding job performance. For example, Forgas (2002) reviews literature on affect regulation showing that regulation of emotion can influence social interaction, requests, negotiation, persuasive communication, group behavior, and altruism, which he proposes are all relevant behaviors in organizational settings.

It is important to note that while prototypical examples of emotion regulation are conscious, emotion regulation has also been speculated to occur at a subconscious level (Gross, 1998). However, Mayer and Salovey (1997) define the concept of emotion regulation as the "conscious regulation of emotions to enhance emotional and intellectual growth" (p. 14). As a result, we exclude subconscious emotion regulation from the present discussion of emotional intelligence, and focus instead on a conscious process, in which emotions must first be perceived and understood before they can be regulated.

In terms of conscious emotion regulation, Gross' (1998) taxonomy of emotion regulatory processes, including attentional deployment, response modulation, situation selection, and situation modification can also facilitate the discussion of emotion regulation's relationship to job performance. To begin, attentional deployment refers to selectively attending to situations based on their emotional valence. Beal, Weiss, Barros, and MacDermid (2005) have explicitly related Gross' process of attentional deployment to job performance by noting that this emotion regulation process could focus an employee on the task at hand. Not only can emotion regulation influence job 
performance by increasing focus on those situations that are emotionally salient, but emotion regulation can also influence job performance through Gross' (1998) process of response modulation, which refers to the direct influence on physiological and cognitive experience of emotion using techniques like relaxation therapy. In their definition of managing emotion, Mayer and Salovey (1997) included the ability to detach from a given emotion when necessary, using processes similar to those described by Gross (1998) as response modulation. The ability to detach from an emotion may be useful in clarifying the boundary between work and family for instance, such that individuals who engage in response modulation can detach from their family-related stresses upon beginning work, allowing attainment of the appropriate emotional state on the job. Moreover, employees engaging in Gross' (1998) process of situation selection can also increase performance by avoiding situations that cause inappropriate emotions at work. For example, an employee may choose not to attend a discussion about employee benefits, because s/he knows that this discussion will be emotion-laden, and s/he needs to focus on work. Furthermore, if this employee is required to attend, s/he may engage in situation modification (Gross, 1998), also known as coping, to reduce the emotional impact of the meeting and return to work with minimal distraction. In sum, the dimension of emotion regulation offers several avenues by which emotional intelligence influences job performance, and it serves as the key element in the cascading model of EI proposed here.

The Cascading Model of EI, Personality, and Cognitive Ability

Now that we have presented a causal rationale for the relationships between EI 
facets and job performance, we acknowledge other important constructs with which EI might potentially overlap in the explanation of performance: personality traits and cognitive ability. Over the years, researchers have shown that personality, namely the "Big Five" traits, predicts performance in a wide variety of jobs (see Barrick \& Mount, 2005). High performance in most jobs requires the individual to be responsible and achievement-driven (Conscientiousness) as well as low in anxiety, insecurity and depression (Emotional Stability). Moreover, we propose that emotional competencies as presented in the cascading model of EI may serve as partial mechanisms by which the personality traits of Conscientiousness and Emotional Stability influence job performance. Conscientious individuals have been described as thorough, organized, methodical, cautious, and careful (McCrae \& Costa, 1992), which are all adjectives that point to individuals who pay extreme attention to detail. In relation to EI, conscientious individuals who are careful and pay great attention to detail would also theoretically take care in attending to details in emotion. That is, conscientious individuals are more likely to pay attention to subtle cues in conversation that are essential to the perception of emotion. Therefore, Conscientiousness is included in the cascading model of EI such that emotion perception is a partial mediator of the relationship between Conscientiousness and job performance (see Figure 1).

In addition, we propose that the relationship between cognitive ability and performance involves the EI dimension of emotion understanding. As noted by Sternberg, Grigorenko, and Kidd (2005), there are nearly two dozen available definitions of cognitive ability, several of which recognize that knowledge is a component of 
cognitive ability. This includes Humphrey's (1979, p. 106) definition of intelligence as an individual's “entire repertoire of acquired skills, knowledge, learning sets, and generalization tendencies considered intellectual in nature that is available at any one period of time" [italics added], and Ackerman's (1996) conceptualization of intelligence as intelligence-as-process, personality, interests, and intelligence-as knowledge. Moreover, it has been shown that the knowledge-related component of cognitive ability is the primary avenue by which cognitive ability influences job performance (Schmidt \& Hunter, 2004). That is, individuals with higher cognitive ability acquire more job-related knowledge, which increases their job performance. This finding that knowledge is a mediator of cognitive ability and performance also applies to the relationship between emotion understanding, cognitive ability, and job performance. As previously mentioned, accurate understanding of emotion represents a body of knowledge concerning which emotions are appropriate in a given context. Thus, we propose that individuals with high cognitive ability would acquire more of the knowledge-base associated with emotion understanding, and perform better as a result. Therefore, we propose that emotion understanding is a partial mediator of the relationship between cognitive ability and job performance.

Finally, we propose that Emotional Stability occupies a similar role involving the EI dimension of emotion regulation. Emotional Stability has been described as a lack of emotionality (Norman, 1963), neuroticism (Eysenck, 1970), and anxiety (Cattell, 1957). Moreover, Emotional Stability/Neuroticism have been related to trait Negative Affect to the extent that the experience of negative emotions is central to the dimension of 
Neuroticism (Watson, \& Clark, 1992). It has also been shown that individuals low in Emotional Stability are more likely to increase their level of worry when performing demanding tasks (Tamir, 2005). This suggests that one way in which individuals who are high on Emotional Stability perform well on the job is through their effective emotion regulation that keeps them characteristically free of anxiety and emotionality. In sum, the cascading model of EI presents emotion perception, emotion understanding, and emotion regulation as partial mediators of the relationship between Conscientiousness and performance, cognitive ability and performance, and Emotional Stability and performance, respectively. We hypothesize that all of the path coefficients presented in the model will be significant.

\section{Incremental Validity of Emotional Intelligence}

Aside from the conceptual model of EI and job performance presented above, there exists another important question from the perspective of selection practitioners: "How large is the incremental validity of EI for predicting job performance, over and above cognitive ability and personality?" The theoretical linkages between personality traits, EI, and job performance discussed above (and specified in the cascading model in Figure 1) are notable in that we propose a conceptual role for EI in which EI is not entirely redundant with these more longstanding personality and ability constructs.

As previously mentioned, EI has been criticized for its overlap with personality traits. Although Eysenck (1998) has suggested EI is redundant with Neuroticism, there is a potentially important conceptual distinction between emotional stability and emotional control. Moreover, there are elements of emotion communication present in emotion 
perception that are not redundant with Conscientiousness. As such, we predict that emotional intelligence will display modest incremental validity over and above the Big Five personality traits.

Hypothesis 1: Emotional intelligence [both (a) ability and (b) mixed] will predict job performance incrementally, over and above the Big Five personality constructs.

Next, we note that the incremental validity of emotional intelligence constructs over general cognitive ability has been questioned (Eysenck, 1998; Murphy, 2006; Schulte, Ree, \& Carretta, 2004). Ability EI, if it is actually an aptitude or ability, might be expected to belong in the positive manifold amongst other, more specific ability concepts (Brown, Le, \& Schmidt, 2006; Spearman, 1904). If this is true, then — while it is still logically possible for a lower-order ability factor to capture unique variance in a criterion (see Judge, Erez, Bono, \& Thoresen, 2003, for a similar argument with regard to core self-evaluations subfacets)—-the theoretical rationale would need to specify aspects of ability EI that are independent of general mental ability. We do not believe this standard is met for ability models of emotional intelligence.

Mixed models of EI, in contrast to ability models of EI, are not theorized to solely reflect an ability construct, and thus may capture elements of performance that are not highly loaded with $g$ (general mental ability). Based on this argument, we predict a unique association of mixed EI with job performance.

Hypothesis 2: Mixed emotional intelligence will predict job performance incrementally, over and above cognitive ability. 


\section{Adverse Impact}

Another potential usage for emotional intelligence measures is a potential reduction of adverse impact against underrepresented minority groups. Adverse impact occurs when the selection ratio of a group is less than $4 / 5$ ths of the selection ratio of the group with the highest selection ratio (Equal Opportunity Employment Commission, 1978). This definition characterizes adverse impact as an administrative term, which results from subgroup differences on psychological constructs that are used as predictors in a selection model. It can be shown that for a given selection ratio, subgroup differences are directly related to adverse impact (i.e., adverse impact and subgroup differences are essentially redundant pieces of information; Newman, Jacobs, \& Bartram, 2007). Thus, we chose to utilize the term adverse impact for the current paper. The potential for EI measures to partly ameliorate Black-White adverse impact stems from the finding of near-zero racial subgroup differences (Van Rooy, Alonso \& Viswesvaran, 2005) in measures of EI. These findings can be theoretically elaborated using Keltner, Gruenfeld, and Anderson's recent model of power (2003). In this model, ethnicity is a determinant of power, and as such, it is implied that minorities should carefully control their emotions to avoid upsetting the powerful (Whites) who control valuable resources. Thus, minority ability to regulate emotion should become greater than that of Whites. Furthermore, in her famous essay "White Privilege: Unpacking the Invisible Knapsack," McIntosh (1990) provides a list of the daily effects of White privilege, such as, "I [Whites] can be pretty sure that my neighbors... will be neutral or pleasant to me" (p. 2). This implies that minorities must wrestle with unpleasant 
responses from other people more frequently than Whites. If Blacks must deal with unpleasant responses more often than Whites do, and are also exposed to more variability in affective responses, then Blacks should develop more accurate perception and regulation of emotion when attempting to deal with these more prevalent unpleasant responses.

Similarly, in regard to male-female adverse impact, the use of EI tests in organizations may actually reduce adverse impact against females that sometimes occurs with the use of cognitive ability tests. Many studies have found that women tend to score higher than men on EI (Day \& Carroll, 2004; Mayer, Caruso, \& Salovey, 1999; Schutte et al., 1998; Van Rooy, Alonso, \& Viswesvaran, 2005), suggesting that EI tests, when used alone, may result in adverse impact against males. The finding that females score higher on EI measures than males is not surprising, given that society commonly views the expression of emotions as unmanly (Brody, 2000). Even at a young age, boys are required to inhibit their emotional expressions more often than girls (Underwood, Coie, \& Herbsman, 1992), and girls are more proficient than boys at "tricking" someone into believing they like something (Brody, 2000). An integrated model of emotion (McClure, 2000) suggests that these early differences are signs of both an early maturation of a neurological subsystem dedicated to emotion in girls, and adherence to social norms. Later in life, this allows females to accurately assess facial expression of emotion better than males (McClure, 2000), which could explain higher EI scores in females than in males. Differences in female-male EI can also be explained through Baron-Cohen's extreme male brain theory of autism (2002). In explaining autism, Baron-Cohen reasons 
that males tend to "systemize", or analyze the world in a series of "if-then" rules more than females, while females tend to "empathize", or attribute mental states to others and respond with appropriate affective responses, more than males. This simple division points to differences in female and male cognition, with females using emotion more than males, which can be seen in higher EI scores for females than males.

As such, EI measures may increase the potential for adverse impact against males, while decreasing the potential for adverse impact against females. Current estimates of subgroup differences in cognitive ability suggest that Whites' average scores on cognitive ability measures are .72 standard deviations above Blacks' average scores (Roth, Bevier, Bobko, Switzer, \& Tyler, 2001). In terms of female-male differences, research suggests that males' average cognitive ability scores are .30 standard deviations above that of females (Lynn \& Irwing, 2004). This estimate is based on a meta-analysis of one particular measure of cognitive ability, Raven's Advanced Progressive Matrices (APM), which many experts believe is among the best markers for $g$ because it is not heavily influenced by knowledge or reading ability(e.g., Humphreys, 1984; Jensen, 1980; Snow, Kyllonen, \& Marshalek, 1984). Because the APM is among the purist measures of cognitive ability, we use Lynn and Irwing's (2004) meta-analytic estimate of sex differences in cognitive ability for the current paper.

Because Black-White subgroup $d$ values for emotional intelligence appear to be smaller than (or opposite in sign from) those for cognitive ability tests, the potential for a composite of EI measures with cognitive measures to reduce adverse impact is strong. 
Given this, the current paper seeks to estimate the extent to which EI measures reduce Black-White adverse impact.

Hypothesis 3a: Emotional intelligence will result in a smaller Black-White subgroup $\mathrm{d}$ than cognitive ability.

Similarly, because male-female subgroup $d$ values for emotional intelligence appear to be in the opposite direction from subgroup $d$ values for cognitive ability, we predict that a composite of EI measures with cognitive ability tests will reduce the potential for adverse impact against females.

Hypothesis 3b: Emotional intelligence will result in a smaller female-male subgroup d than cognitive ability. 


\section{METHOD}

\section{Published Effect Sizes}

In order to estimate the incremental validity of emotional intelligence measures and test the cascading model of EI, we constructed a correlation matrix based on metaanalytic estimates (as advocated by Viswesvaran \& Ones, 1995). The existing metaanalytic correlations and original meta-analytic correlations to be calculated as part of the current study amongst EI and its dimensions, job performance, Big Five traits, and cognitive ability as well as subgroup differences in race and sex are displayed in Table 3. The existing correlation estimates in Table 3 are based on 21 published meta-analyses and are corrected for attenuation in the predictor and criterion. The minimum $N$ for personality intercorrelations is 135,539 (Ones, 1993), and the minimum $N$ for correlations between personality factors and cognitive ability is 11,190 (Judge, Jackson, Shaw, Scott, \& Rich, 2007). Job performance validities come from Hunter and Hunter (1984; $N=32,124$, for cognitive tests) and Barrick, Mount, and Judge (2001; minimum $N=23,225$ for Big Five personality inventories). The estimate taken from Hunter and Hunter (1984) was uncorrected for range restriction by assuming a value of .80 for the ratio of the variance of the restricted group to the variance of the unrestricted group in the correction formula for range restriction (Sackett \& Yang, 2000). Estimates taken from Barrick et al. (2001) reflect overall work performance, and are composed of independent primary samples.

In order to test potential adverse impact attributable to emotional intelligence measures, we also compiled meta-analytic estimates of Black-White and female-male 
Table 3

Meta-Analytic Correlation Matrix of Previous Meta-Analytic Estimates

\begin{tabular}{|c|c|c|c|c|c|c|c|c|c|c|c|c|c|}
\hline & & & & & & & & & & & & $\begin{array}{l}\text { Female- } \\
\text { Male }\end{array}$ & $\begin{array}{l}\text { Black- } \\
\text { White }\end{array}$ \\
\hline & 1. & 2. & 3. & 4. & 5. & 6. & 7. & 8. & 9. & 10. & 11. & $d$ & $d$ \\
\hline 1. Overall EI & 1.0 & & & & & & & & & & & $*$ & $*$ \\
\hline $\begin{array}{l}\text { 2. Emotion } \\
\text { Perception }\end{array}$ & $*$ & 1.0 & & & & & & & & & & $*$ & $*$ \\
\hline $\begin{array}{l}\text { 3. Emotion } \\
\text { Understanding } \\
\text { 4. Emotion }\end{array}$ & $*$ & $*$ & 1.0 & & & & & & & & & $*$ & $*$ \\
\hline $\begin{array}{l}\text { Facilitation } \\
\text { 5. Emotion }\end{array}$ & $*$ & $*$ & $*$ & 1.0 & & & & & & & & $*$ & $*$ \\
\hline Regulation & $*$ & $*$ & $*$ & $*$ & 1.0 & & & & & & & $*$ & $*$ \\
\hline 6. Agreeableness & $*$ & $*$ & $*$ & $*$ & $*$ & 1.0 & & & & & & $\begin{array}{c}.39^{\mathrm{a}} \\
\dagger / 151106\end{array}$ & $\begin{array}{c}-.02^{\mathrm{a}} \\
\dagger / 63274\end{array}$ \\
\hline $\begin{array}{l}\text { 7. Conscien- } \\
\text { tiousness }\end{array}$ & $*$ & $*$ & $*$ & $*$ & $*$ & $\begin{array}{c}.27^{\mathrm{b}} \\
344 / 162975\end{array}$ & 1.0 & & & & & $\begin{array}{c}.08^{\mathrm{a}} \\
+/ 217357\end{array}$ & $\begin{array}{c}-.06^{\mathrm{a}} \\
+/ 172576\end{array}$ \\
\hline $\begin{array}{l}\text { 8. Emotional } \\
\text { Stability }\end{array}$ & $*$ & $*$ & $*$ & $*$ & $*$ & $.25^{\mathrm{b}}$ & $.26^{\mathrm{b}}$ & 10 & & & & $\begin{array}{c}-.24^{\mathrm{a}} \\
+/ 166244\end{array}$ & $\begin{array}{c}.04^{\mathrm{a}} \\
+\quad 60061\end{array}$ \\
\hline 9. Extraversion & & & & & & $\begin{array}{c}561 / 4156 / 9 \\
.17^{\mathrm{b}}\end{array}$ & $\begin{array}{c}58 / 1490290 \\
.00^{\mathrm{b}}\end{array}$ & $\begin{array}{l}1.0 \\
.19^{\mathrm{b}}\end{array}$ & & & & $-.09^{\mathrm{a}}$ & $-.10^{\mathrm{a}}$ \\
\hline 10. Openness & $*$ & $*$ & $*$ & $*$ & $*$ & $\begin{array}{c}234 / 135529 \\
.11^{\mathrm{b}}\end{array}$ & $\begin{array}{c}632 / 683001 \\
-.06^{b}\end{array}$ & $\begin{array}{c}710 / 440440 \\
.16^{\mathrm{b}}\end{array}$ & $\begin{array}{c}1.0 \\
.17^{\mathrm{b}}\end{array}$ & & & $\begin{array}{c}\dagger / 358485 \\
-.07^{\mathrm{a}}\end{array}$ & $\begin{array}{c}\dagger / 67138 \\
-.21^{\mathrm{a}}\end{array}$ \\
\hline 11. Cognitive & $*$ & $*$ & $*$ & $*$ & $*$ & $\begin{array}{c}236 / 144205 \\
.00^{c}\end{array}$ & $\begin{array}{c}338 / 356680 \\
-.04^{c}\end{array}$ & $\begin{array}{c}423 / 254937 \\
.09^{c}\end{array}$ & $\begin{array}{c}418 / 252004 \\
.02^{c}\end{array}$ & $\begin{array}{l}1.0 \\
.22^{\mathrm{c}}\end{array}$ & & $\begin{array}{c}\dagger / 51550 \\
-.30^{\mathrm{d}}\end{array}$ & $\begin{array}{c}+/ 9862 \\
-.72^{\mathrm{e}}\end{array}$ \\
\hline $\begin{array}{l}\text { Ability } \\
\text { 12. Job }\end{array}$ & $*$ & $*$ & $*$ & $*$ & $*$ & $\begin{array}{l}38 / 11190 \\
.10^{f}\end{array}$ & $\begin{array}{l}56 / 15429 \\
.23^{\mathrm{f}}\end{array}$ & $\begin{array}{l}61 / 21404 \\
.12^{\mathrm{f}}\end{array}$ & $\begin{array}{l}61 / 21602 \\
.12^{f}\end{array}$ & $\begin{array}{c}46 / 13182 \\
.05^{\mathrm{f}}\end{array}$ & $\begin{array}{c}1.0 \\
.43^{\mathrm{g}}\end{array}$ & $\begin{array}{c}10 / 9631 \\
.11^{\mathrm{h}}\end{array}$ & $\begin{array}{c}18 / 31990 \\
-.35^{\mathrm{i}}\end{array}$ \\
\hline Performance & $*$ & $*$ & $*$ & $*$ & $*$ & $206 / 36210$ & $239 / 48100$ & $224 / 38817$ & $222 / 39432$ & $143 / 23225$ & $425 / 32124$ & $55 / 40195$ & $37 / 84295$ \\
\hline
\end{tabular}

Note. Each cell contains the correlation corrected for attenuation, followed by $k$ number of effect sizes and $N$ sample size. $\dagger$ unknown number of effect sizes. ${ }^{\mathrm{a}}$ Hough, Oswald, \& Ployhart, 2001; ${ }^{\mathrm{b}}$ Ones, 1993; ${ }^{\mathrm{c} J u d g e, ~ J a c k s o n, ~ S h a w, ~ S c o t t, ~ \& ~ R i c h, ~ 2007 ; ~}{ }^{\mathrm{d}}$ Lynn \& Irwing, 2004; ${ }^{\mathrm{e}}$ Roth, Bevier, Bobko, Switzer, \& Tyler, 2001; ${ }^{\mathrm{f}}$ Barrick, Mount, \& Judge, 2001; ${ }^{\mathrm{g}}$ Hunter \& Hunter, 1984; ${ }^{\mathrm{h}}$ Roth \& Purvis, $2007 ;{ }^{\mathrm{i}}$ Roth, Huffcutt, \& Bobko, 2003. 
subgroup $d$ from fourteen published meta-analyses (see Hough, Oswald, \& Ployhart, 2001; Lynn \& Irwing, 2004; Roth, BeVier, Bobko, Switzer, \& Tyler, 2001; Roth, Huffcutt \& Bobko, 2003; minimum $N=9,861$ ). These existing estimates as well as the meta-analytic $d$ values to be calculated as part of this study are presented in Table 3 . Original Meta-Analyses

Estimates for emotional intelligence come from several original meta-analyses. To identify studies for inclusion, a search of the American Psychological Association's PsycINFO (1887-2007), Google Scholar, and Dissertation Abstracts International (18612007) was conducted for keywords (and several variations of the following keywords): emotional intelligence, cognitive ability, personality, job performance, race, and sex. Studies used in Van Rooy and colleagues' $(2004,2005)$ meta-analyses were also obtained from their reference list. References of all available studies and relevant reviews were searched for studies that were missed in previous searches, and several authors were contacted for unpublished work relating to emotional intelligence. This search identified 171 studies which were then examined for congruence with several inclusion criteria. Following Van Rooy and Viswesvaran (2004), a study was only included if it used a measure that was specifically referred to as a measure of emotional intelligence. This resulted in the inclusion of the following measures of emotional intelligence: the Mayer-Salovey-Caruso Emotional Intelligence Test (MSCEIT; Mayer et al., 2003), the Multifactor Emotional Intelligence Scale (MEIS; Mayer et al., 1999), the Emotional Quotient-Inventory (EQ-i; Bar-On, 1997), the Emotional Competence Inventory (ECI; Sala, 2002); the Emotional Intelligence Scale (EIS; Schutte et al., 1998), 
the Wong and Law Emotional Intelligence Scale (WLEIS; Wong \& Law, 2002), the Trait Emotional Intelligence Questionnaire (TEIQue; Petrides \& Furnham, 2003), the Trait Meta-Mood Scale (TMMS; Salovey et al., 1995), Swinburne University Emotional Intelligence Test (SUEIT; Palmer \& Stough, 2001), the Bedwell Emotional Judgment Inventory (EJI; Bedwell, 2003), the Workgroup Emotional Intelligence Profile (WEIP; Jordan et al., 2002), Tett and colleague's scale of emotional intelligence (Tett, Fox, \& Wang, 2005), Freudenthaler and Neubauer's scale of emotion abilities (Freudenthaler \& Neubauer, 2005), the Japanese Emotional Intelligence Scale (Uchiyama, Shimai, Utsugi, \& Otake, 2001), Sjoberg's scale of EI (Sjoberg, 2001a), Alfolabi and Ehigie's scale of EI (Alfolabi \& Ehigie, 2005), the General Emotional Intelligence Scale (GEIS; Mehrabian, 2001), the Carrothers, Gregory, and Gallagher EI scale (Carrothers, Gregory, \& Gallagher, 2000), and the Emotional Accuracy Research Scale (EARS; Mayer \& Geher, 1996). The remaining studies were then examined for relationships with job performance, cognitive ability, personality, race, sex, and intercorrelations of EI dimensions. Studies regarding the relationship between EI and job performance were included if: (a) enough information to calculate a correlation between EI and job performance was provided, (b) ratings of job performance were provided by a supervisor, and (c) the study involved employed individuals [this does not include students acting as if they were managers who provide performance ratings of students acting as subordinates (e.g., Day \& Carroll, 2004)]. Studies were also excluded if: (a) job performance was manipulated, and (b) academic performance was considered job performance (e.g., Holbrook, 1997). Studies concerning the relationship between 
cognitive ability and EI were included for the following cognitive ability measures: Weschler Adult Intelligence Scale (WAIS; Wechsler, 1955), Wechsler Abbreviated Scale of Intelligence (WASI; Wechsler, 1999), Wonderlic Personnel Test (WPT; 2000), Raven's Advanced Progressive Matrices (RAPM; Raven, 2003), Scholastic Aptitude Test (SAT; College Entrance Examination Board and Educational Testing Service, 1995), Shipley Institute of Living Scale (SILS; Western Psychological Services, 1967), Army Alpha Intelligence Scale (AAIS; Yerkes, 1921), General Aptitude Test Battery (GATB; United States Department of Labor, 1970), Armed Services Vocational Aptitude Battery (ASVAB; U.S. Department of Defense, 1984), ACT (ACT Inc., 2002), Watson-Glaser Critical Thinking Appraisal (WGCTA; Watson \& Glaser, 1994), German Intelligence Structure Test, (IST; Amthauer, Brocke, Liepmann, \& Beauducel, 2001), Baddeley Reasoning Test (BRT; Baddeley, 1968), Horn's vocabulary and matrices tests (1975), S \& M Test of Mental Rotation Ability (Philips \& Rawles, 1979), Canadian Forces Aptitude Test (CFAT; Albert, 1998), Gf/Gc Quickie Test Battery (Stankov, 1997), the Verbal and Spatial Abilities Test (Heim, 1968), General Adult Mental Ability scale (GAMA; Naglieri \& Bardos, 1997), and STAT intelligence test (Sternberg, 1993). The only ostensible tests of cognitive ability that were deliberately excluded from the analysis were Cattell's culture-fair test of $g$ (Cattell \& Cattell, 1973) and student GPA. Studies speaking to the relationship between EI and personality were included if a measure of Big Five personality traits was administered and enough information to calculate a correlation between any one or more of the Big Five personality traits was provided. Studies involving race differences in EI were only included if enough 
information was provided to calculate a standardized mean difference, or $d$ value, and if this $d$ value involved a standardized mean difference between Black and White participants. Similarly, studies involving sex differences in EI were only included if enough information was provided to calculate a $d$ value. In addition, all studies being considered for the current meta-analysis were required to provide the sample size and consist of primarily adult participants (over age 16) in order to be included. These inclusion criteria resulted in a final database consisting of 106 usable studies, with a total sample size of 29,027 .

\section{Data Coding}

Studies that passed the inclusion criteria were then coded on several attributes. Each study was coded for an effect size between EI and either job performance, personality, cognitive ability, race, or sex, as well as the measures used for relevant variables, reliability of these measures, sample size, and participant characteristics. All measures of EI were also coded for the construct measured (ability or mixed) and method employed (self-report or performance-based). Any EI measure purported to be based on an ability model was subsequently classified as an ability measure. This included the following EI measures: MCEIT, MEIS, WLEIS, EIS, TEIQue, and WEIP. All other EI measures were classified as mixed measures. Regarding the method of each EI measure, any measure scored by marking questions as correct or incorrect based on expert or consensus scores was considered a performance-based measure (i.e., MSCEIT and MEIS), and all other measures were coded as self-report measures. As a result of the construct and method coding, all EI measures were classified as one of the following 
construct-method pairings: self-report ability, self-report mixed, performance-based ability, or performance-based mixed (see Table 1). Because no studies involved performance-based mixed measures of EI, we hereafter refer to performance-based ability measures as performance-based measures. Finally, all ability-based measures of EI (both self-report and performance-based) were coded for relationships between dimensions of EI and any relevant variable, as well as intercorrelations among EI dimensions.

In order to determine the accuracy of the coding process, a second individual was asked to code all articles identified in the original search. The agreement between the two coders at the item-level was $98 \%$, and any disagreements were discussed and resolved between the coders.

\section{Data Analysis}

The current meta-analytic procedures followed the Hunter and Schmidt (2004) methods. Because the current meta-analysis attempts to determine the theoretical relationship between EI and various variables, all effect sizes were corrected for attenuation due to measurement error in both the predictor and criterion. In an effort to use independent sample effects, only one effect size per sample was included in each meta-analysis. If a sample provided multiple, facet-level effect sizes for one relationship, a composite correlation was constructed (Nunnally, 1978; see Judge, Thoresen, Bono, \& Patton, 2001).

Confidence intervals were constructed around the sample-size weighted mean using the standard error in order to address the accuracy of the mean estimate of the 
relationships examined (Schmidt, Hunter, \& Raju, 1988). Credibility intervals were also calculated around the mean corrected effect size using the standard deviation of the mean corrected effect size in order to indicate the generalizability of each relationship across situations (Whitener, 1990). The presence of moderators is indicated when the lower bound of the credibility interval exceeds zero. As previously mentioned, all primary studies were coded for construct-method pairing and relationships between EI dimensions and relevant variables. These two moderators (construct-method pairing and EI dimensions) were investigated using credibility intervals and the amount of variance explained by artifacts (Hunter \& Schmidt, 2004).

In order to test our hypotheses concerning the cascading model of EI (Figure 1), we use the meta-matrix shown in Table 4 (see Shadish, 1996). This meta-matrix contains attenuation-corrected correlations based only on the MEIS and MSCEIT measures of EI. We chose to include only the MEIS and MSCEIT as measures of EI for this portion of the analyses (i.e., testing the cascading model in Figure 1) because the primary studies that reported validities for the dimensions of EI coincidentally all employed the MEIS and MSCEIT. Standard errors for these analyses are based upon the harmonic mean $N$ from the emotional intelligence meta-analyses (Viswesvaran \& Ones, 1995). To test the mediated model (Figure 1), an SEM approach (James \& Brett, 1984) was used. As recommended by James, Mulaik, and Brett (2006), this method is more appropriate than the Baron and Kenny (1986) method for tests of full mediation, as predicted in the cascading model of EI. Fit of the hypothesized model was estimated using LISREL 8.80 (Jöreskog \& Sörbom, 2006). Only true score correlations based on the MEIS or MSCEIT 
Table 4

Meta-Analytic Correlation Matrix of MEIS/MSCEIT, Job Performance, Personality, Cognitive Ability, Race, and Sex

\begin{tabular}{|c|c|c|c|c|c|c|c|c|c|c|c|}
\hline & 1. & 2. & 3. & 4. & 5. & 6. & 7. & 8. & 9. & 10. & 11. \\
\hline 1. Overall EI & 1.0 & & & & & & & & & & \\
\hline 2. Emotion & .76 & & & & & & & & & & \\
\hline Perception & $12 / 2577$ & 1.0 & & & & & & & & & \\
\hline 3. Emotion & .83 & .47 & & & & & & & & & \\
\hline Understanding & $12 / 2577$ & $12 / 2577$ & 1.0 & & & & & & & & \\
\hline 4. Emotion & .87 & .63 & .63 & & & & & & & & \\
\hline Facilitation & $12 / 2577$ & $12 / 2577$ & $12 / 2577$ & 1.0 & & & & & & & \\
\hline 5. Emotion & .76 & .33 & .57 & .54 & & & & & & & \\
\hline Regulation & $\begin{array}{c}12 / 2577 \\
.30\end{array}$ & $\begin{array}{c}12 / 2577 \\
.15\end{array}$ & $\begin{array}{c}12 / 2577 \\
.11\end{array}$ & $\begin{array}{c}12 / 2577 \\
.16\end{array}$ & $\begin{array}{l}1.0 \\
.31\end{array}$ & & & & & & \\
\hline 6. Agreeableness & $24 / 3583$ & $21 / 3187$ & $21 / 3187$ & $21 / 3187$ & $21 / 3187$ & 1.0 & & & & & \\
\hline $\begin{array}{l}\text { 7. Conscien- } \\
\text { tiousness }\end{array}$ & $\begin{array}{c}.12 \\
23 / 3451\end{array}$ & $\begin{array}{c}.28 \\
21 / 3187\end{array}$ & $\begin{array}{c}.08 \\
21 / 3187\end{array}$ & $\begin{array}{c}.09 \\
21 / 3187\end{array}$ & $\begin{array}{c}.15 \\
21 / 3187\end{array}$ & $\begin{array}{c}.27^{\mathrm{a}} \\
344 / 162975\end{array}$ & 1.0 & & & & \\
\hline 8. Emotional & .21 & .12 & .08 & .11 & .13 & $.25^{\mathrm{a}}$ & $.26^{\mathrm{a}}$ & & & & \\
\hline Stability & $\begin{array}{c}24 / 3583 \\
.18\end{array}$ & $\begin{array}{c}21 / 3187 \\
.07\end{array}$ & $\begin{array}{c}21 / 3187 \\
.05\end{array}$ & $\begin{array}{c}21 / 3187 \\
.08\end{array}$ & $\begin{array}{c}21 / 3187 \\
.16\end{array}$ & $\begin{array}{c}561 / 415679 \\
.17^{\mathrm{a}}\end{array}$ & $\begin{array}{c}587 / 490296 \\
.00^{\mathrm{a}}\end{array}$ & $\begin{array}{l}1.0 \\
.19^{\mathrm{a}}\end{array}$ & & & \\
\hline 9. Extraversion & $\begin{array}{c}23 / 3451 \\
.23\end{array}$ & $\begin{array}{c}21 / 3187 \\
.05\end{array}$ & $\begin{array}{c}21 / 3187 \\
.16\end{array}$ & $\begin{array}{c}21 / 3187 \\
.07\end{array}$ & $\begin{array}{c}21 / 3187 \\
.16\end{array}$ & $\begin{array}{c}234 / 135529 \\
.11^{\mathrm{a}}\end{array}$ & $\begin{array}{c}632 / 683001 \\
-.06^{\mathrm{a}}\end{array}$ & $\begin{array}{c}710 / 440440 \\
.16^{\mathrm{a}}\end{array}$ & $\begin{array}{l}1.0 \\
.17^{\mathrm{a}}\end{array}$ & & \\
\hline 10. Openness & $23 / 3451$ & $21 / 3187$ & $21 / 3187$ & $21 / 3187$ & $21 / 3187$ & $236 / 144205$ & $338 / 356680$ & $423 / 254937$ & $418 / 252004$ & 1.0 & \\
\hline $\begin{array}{l}\text { 11. Cognitive } \\
\text { Ability }\end{array}$ & $\begin{array}{c}.26 \\
19 / 3205\end{array}$ & $\begin{array}{c}.10 \\
22 / 4421\end{array}$ & $\begin{array}{c}.39 \\
19 / 3682\end{array}$ & $\begin{array}{c}.19 \\
21 / 4292\end{array}$ & $\begin{array}{c}.17 \\
20 / 3988\end{array}$ & $\begin{array}{c}.00^{\mathrm{b}} \\
38 / 11190\end{array}$ & $\begin{array}{c}-.04^{\mathrm{b}} \\
56 / 15429\end{array}$ & $\begin{array}{c}.09^{\mathrm{b}} \\
61 / 21404\end{array}$ & $\begin{array}{c}.02^{\mathrm{b}} \\
61 / 21602\end{array}$ & $\begin{array}{c}.22^{\mathrm{b}} \\
46 / 13182\end{array}$ & 1.0 \\
\hline $\begin{array}{l}\text { 12. Job } \\
\text { Performance }\end{array}$ & $\begin{array}{c}.33 \\
17 / 2222 \\
\end{array}$ & $\begin{array}{c}.26 \\
3 / 191\end{array}$ & $\begin{array}{c}.28 \\
3 / 191 \\
\end{array}$ & $\begin{array}{c}.20 \\
3 / 191\end{array}$ & $\begin{array}{c}.29 \\
3 / 191 \\
\end{array}$ & $\begin{array}{c}.10^{c} \\
206 / 36210\end{array}$ & $\begin{array}{c}.23^{\mathrm{c}} \\
239 / 48100\end{array}$ & $\begin{array}{c}.12^{\mathrm{c}} \\
224 / 38817\end{array}$ & $\begin{array}{c}.12^{\mathrm{c}} \\
222 / 39432\end{array}$ & $\begin{array}{c}.05^{\mathrm{c}} \\
143 / 23225\end{array}$ & $\begin{array}{c}.43^{\mathrm{d}} \\
425 / 32124\end{array}$ \\
\hline
\end{tabular}

Note. Each cell contains the correlation corrected for attenuation, followed by $k$ number of effect sizes and $N$ sample size. ${ }^{\mathrm{a}}$ Ones, 1993

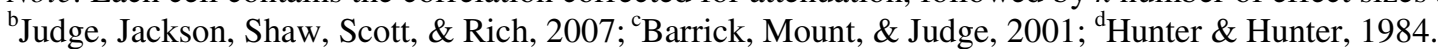


(corrected for unreliability) were used to test the hypothesized model. When examining the fit of the model, the following fit indices are presented: room-mean-square error of approximation (RMSEA), non-normed fit index (NNFI), comparative fit index (CFI), standardized root-mean-residual (SRMR), and $\chi^{2}$. As recommended by Hu and Bentler (1999), $\chi^{2}$ is heavily-dependent on sample size, such that large sample sizes may result in significant $\chi^{2}$ values even with good fit. Thus, $\chi^{2}$ results are presented, although not interpreted. CFI and NNFI are less-dependent on sample-size, and are therefore presented and interpreted, with Hu and Bentler's (1999) cutoff of .95 or greater indicating relatively good fit. In addition, SRMR and RMSEA are also presented and interpreted using Hu and Bentler's (1999) cutoff of .08 or lower for SRMR and .06 or lower for RMSEA as indicators of relatively good fit.

To test our incremental validity hypotheses, we ran a series of multiple regression models based upon the meta-matrix in Table 5. Table 5 contains correlations observed correlations, except in the case of job performance correlations, which are corrected only for measurement error in the criterion. We chose to include these operational validities in our estimation of incremental validity because we were interested in the practical relationship between EI and job performance, in which predictor scores are not corrected. In order to calculate Big Five personality trait operational validities, we corrected the observed correlations found in Barrick et al. (2001) for criterion unreliability using .52 as an estimate of criterion unreliability (see Viswesvaran, Ones, \& Schmidt, 1996). In order to calculate correlations between Big Five personality and cognitive ability found in Judge et al. (2007), we uncorrected the 
Table 5

Meta-Analytic Correlation Matrix of Performance-Based Ability EI, Self-Report Ability EI,

Self-Report Mixed EI, Job Performance, Personality, and Cognitive Ability

\begin{tabular}{lccccccccc}
\hline & 1. & 2. & 3. & 4. & 5. & 6. & 7. & 8. & 9. \\
\hline 1. Performance-Based Ability EI & 1.0 & & & & & & & & \\
2. Self-Report Ability EI & $\dagger$ & 1.0 & & & & & & & \\
3. Self-Report Mixed EI & $\dagger$ & $\dagger$ & 1.0 & & & & & & \\
4. Agreeableness & .25 & .26 & .36 & 1.0 & & & & & \\
5. Conscientiousness & .12 & .32 & .33 & $.31^{\mathrm{a}}$ & 1.0 & & & & \\
6. Emotional Stability & .17 & .34 & .45 & $.37^{\mathrm{a}}$ & $.28^{\mathrm{a}}$ & 1.0 & & & \\
7. Extraversion & .15 & .27 & .40 & $.27^{\mathrm{a}}$ & $.17^{\mathrm{a}}$ & $.23^{\mathrm{a}}$ & 1.0 & & \\
8. Openness & .18 & .24 & .26 & $.18^{\mathrm{a}}$ & $.16^{\mathrm{a}}$ & $.20^{\mathrm{a}}$ & $.30^{\mathrm{a}}$ & 1.0 & \\
9. Cognitive Ability & .22 & .00 & .09 & $.00^{\mathrm{b}}$ & $-.03^{\mathrm{b}}$ & $.08^{\mathrm{b}}$ & $.02^{\mathrm{b}}$ & $.18^{\mathrm{b}}$ & 1.0 \\
10. Job Performance & .27 & .18 & .39 & $.08^{\mathrm{c}}$ & $.17^{\mathrm{c}}$ & $.08^{\mathrm{c}}$ & $.08^{\mathrm{c}}$ & $.04^{\mathrm{c}}$ & $.41^{\mathrm{d}}$ \\
\hline
\end{tabular}

Note. Correlations with job performance are corrected for attenuation in the criterion. All other correlations are observed correlations. $\dagger$ indicates an unknown correlation. ${ }^{\mathrm{a} O n e s, ~ 1993 ; ~}{ }^{\mathrm{b}} \mathrm{Judge}$, Jackson, Shaw, Scott, \& Rich, 2007; ${ }^{\mathrm{c} B a r r i c k, ~ M o u n t, ~ \& ~ J u d g e, ~ 2001 ; ~}{ }^{\mathrm{d}}$ Hunter \& Hunter, 1984.

Judge et al. (2007) correlations assuming a reliability of .90 for cognitive ability measures and substituting unit-weighted internal consistency reliabilities found in Viswesvaran and Ones (2000, p. 231) for the reliability of personality measures.

To estimate incremental validity, we first regressed job performance onto Big Five personality factors and each EI construct-method pairing (Models I, II, and III). Next, we regressed performance onto cognitive ability and each of the EI constructmethod pairings (Models IV, V and VI). Finally, we assessed the incremental validity of each construct-method pairing of EI above a composite of both cognitive ability and Big Five traits (Model VII, VIII, and IX).

To test Hypothesis 3a and 3b, we calculated Black-White and female-male subgroup $d$ values for each construct-method EI pairing. We conducted additional analyses to estimate reduction in Black-White and female-male subgroup $d$ when EI is used in combination with additional predictors (i.e., cognitive ability and Big Five 
personality traits) using Equation 1. The formula for subgroup $d$ of a unit-weighted composite is (Ghiselli, Campbell, \& Zedeck, 1981):

$$
d_{\text {composite }}=\frac{\sum_{i=1}^{k} d_{i}}{\sqrt{k+k(k+1) r_{i i}}},
$$

where $d_{i}$ 's are the subgroup $d$ estimates for each of the $k$ predictors, and $r_{i i}$ is the average correlation among the predictors. Subgroup $d$ estimates used to construct composite $d$ values are presented in Table 6.

Table 6

Estimates of Female-Male and Black-White Subgroup d

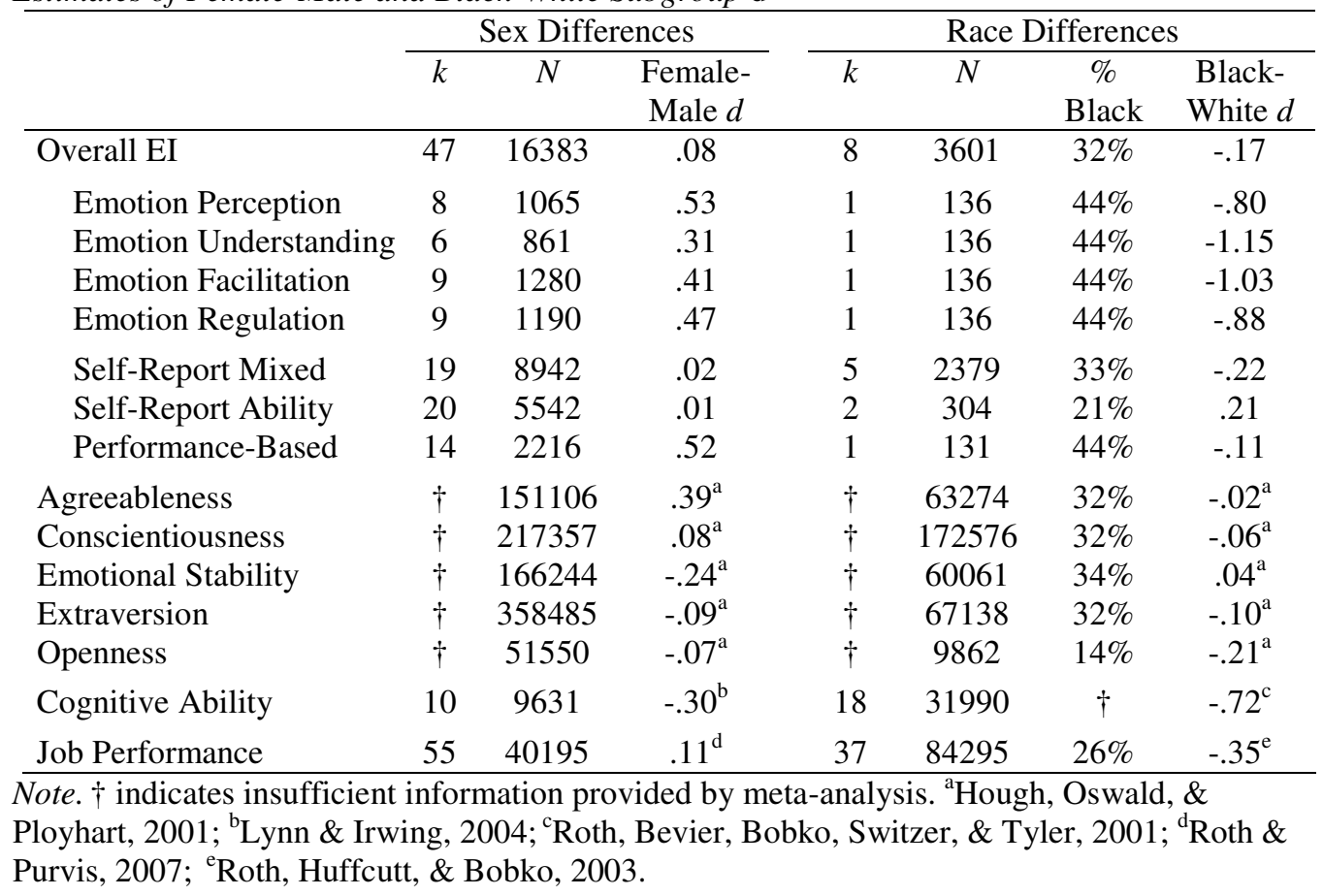




\section{RESULTS}

\section{Meta-Analytic Estimates}

The meta-analytic correlation matrix containing the relationships between EI,

dimensions of EI, personality, job performance and cognitive ability are presented in Table 7 and results regarding subgroup differences for race and sex are presented in Table 6. All correlations and $d$ values presented in Tables 6 and 7 have been corrected for unreliability in the predictor and criterion. Tables 8 and 9 present additional information concerning these meta-analytic estimates as well as moderator analyses.

Emotional Intelligence and Big Five Personality Trait Meta-Analytic Estimates. As shown in Table 8, the total number of effect sizes included in the meta-analytic estimates for EI and Big Five personality traits ranged from 58 to 60 and the total sample size varied between 18,170 and 18,462. The strongest relationship between a Big Five personality trait and overall EI occurred between Emotional Stability and EI $(\rho=.39)$. Additional Big Five and EI relationships were $\rho=.34$ for Agreeableness, followed by $\rho$ $=.33$ for Extraversion, $\rho=.32$ for Conscientiousness, and $\rho=.27$ for Openness.

Each of these estimates exhibited considerable variance, as seen in the standard deviations of the corrected correlations, which ranged from .16 for Agreeableness to .27 for Extraversion. Moreover, the credibility interval regarding the relationship between EI and Extraversion contained zero, indicating that the relationship between EI and Extraversion may not generalize across situations. All other credibility intervals between EI and Big Five personality traits did not contain zero, indicating the generalizability of the relationship between EI and these traits across situations. However, the percent of 
Table 7

Meta-Analytic Correlation Matrix of Emotional Intelligence, Job Performance, Personality, and Cognitive Ability

\begin{tabular}{|c|c|c|c|c|c|c|c|c|c|c|c|}
\hline & 1. & 2. & 3. & 4. & 5. & 6. & 7. & 8. & 9. & 10. & 11. \\
\hline 1. Overall EI & 1.0 & & & & & & & & & & \\
\hline 2. Emotion & .76 & & & & & & & & & & \\
\hline Perception & $12 / 2577$ & 1.0 & & & & & & & & & \\
\hline 3. Emotion & .83 & .47 & & & & & & & & & \\
\hline Understanding & $12 / 2577$ & $12 / 2577$ & 1.0 & & & & & & & & \\
\hline 4. Emotion & .87 & .63 & .63 & & & & & & & & \\
\hline Facilitation & $12 / 2577$ & $12 / 2577$ & $12 / 2577$ & 1.0 & & & & & & & \\
\hline 5. Emotion & .76 & .33 & .57 & .54 & & & & & & & \\
\hline Regulation & $12 / 2577$ & $12 / 2577$ & $12 / 2577$ & $12 / 2577$ & 1.0 & & & & & & \\
\hline \multirow{2}{*}{ 6. Agreeableness } & .34 & .15 & .12 & .17 & .30 & & & & & & \\
\hline & $59 / 18302$ & $23 / 3582$ & $22 / 3374$ & $23 / 3582$ & $22 / 3374$ & 1.0 & & & & & \\
\hline \multirow{2}{*}{$\begin{array}{l}\text { 7. Conscien- } \\
\text { tiousness }\end{array}$} & .32 & .28 & .09 & .11 & .16 & $.27^{\mathrm{a}}$ & & & & & \\
\hline & $60 / 18462$ & $23 / 2582$ & $22 / 3374$ & $23 / 3582$ & $22 / 3374$ & $344 / 162975$ & 1.0 & & & & \\
\hline \multirow{2}{*}{$\begin{array}{l}\text { 8. Emotional } \\
\text { Stability }\end{array}$} & .39 & .12 & .09 & .11 & .17 & $.25^{\mathrm{a}}$ & $.26^{\mathrm{a}}$ & & & & \\
\hline & $60 / 18416$ & $24 / 3696$ & $22 / 3374$ & $23 / 3582$ & $22 / 3374$ & $561 / 415679$ & $587 / 490296$ & 1.0 & & & \\
\hline \multirow[t]{2}{*}{ 9. Extraversion } & .33 & .09 & .07 & .10 & .18 & $.17^{\mathrm{a}}$ & $.00^{\mathrm{a}}$ & $.19^{\mathrm{a}}$ & & & \\
\hline & $60 / 18450$ & $24 / 3696$ & $22 / 3374$ & $23 / 3582$ & $22 / 3374$ & $234 / 135529$ & $632 / 683001$ & $1710 / 440440$ & 1.0 & & \\
\hline \multirow[t]{2}{*}{ 10. Openness } & .27 & .07 & .18 & .10 & .16 & $.11^{\mathrm{a}}$ & $-.06^{\mathrm{a}}$ & $.16^{\mathrm{a}}$ & $.17^{\mathrm{a}}$ & & \\
\hline & $58 / 18170$ & $23 / 3582$ & $22 / 3374$ & $23 / 3582$ & $22 / 3374$ & $236 / 144205$ & $338 / 356680$ & $423 / 254937$ & $418 / 252004$ & 1.0 & \\
\hline 11. Cognitive & .16 & .10 & .39 & .18 & .16 & $.00^{\mathrm{b}}$ & $-.04^{\mathrm{b}}$ & $.09^{\mathrm{b}}$ & $.02^{\mathrm{b}}$ & $.22^{\mathrm{b}}$ & \\
\hline Ability & $54 / 10519$ & $20 / 4608$ & $19 / 4479$ & $17 / 3869$ & $18 / 4175$ & $38 / 11190$ & $56 / 15429$ & $61 / 21404$ & $61 / 21602$ & $46 / 13182$ & 1.0 \\
\hline 12. Job & .33 & .26 & .28 & .20 & .29 & $.10^{\mathrm{c}}$ & $.23^{\mathrm{c}}$ & $.12^{\mathrm{c}}$ & $.12^{\mathrm{c}}$ & $.05^{\mathrm{c}}$ & $.43^{\mathrm{d}}$ \\
\hline Performance & $17 / 2222$ & $3 / 191$ & $3 / 191$ & $3 / 191$ & $3 / 191$ & $206 / 36210$ & $239 / 48100$ & $224 / 38817$ & $222 / 39432$ & $143 / 23225$ & $25 / 32124$ \\
\hline
\end{tabular}

Note. Each cell contains the correlation corrected for attenuation, followed by $k$ number of effect sizes and $N$ sample size. $\dagger$ indicates an unknown number of effect sizes. ${ }^{\mathrm{a} O n e s, ~ 1993 ; ~}{ }^{\mathrm{b}}$ Judge, Jackson, Shaw, Scott, \& Rich, 2007; ${ }^{\mathrm{c}}$ Barrick, Mount, \& Judge, $2001 ;{ }^{\mathrm{d}}$ Hunter \& Hunter, 1984. 
Table 8

Meta-Analytic Results for Emotional Intelligence and Its Dimensions with Personality Traits, Cognitive Ability, and Job Performance

\begin{tabular}{|c|c|c|c|c|c|c|c|c|c|c|}
\hline & $k$ & $N$ & $r$ & $\rho$ & SD $\rho$ & $\begin{array}{l}95 \% \\
\text { CI-L }\end{array}$ & $\begin{array}{l}95 \% \\
\text { CI-U }\end{array}$ & $\begin{array}{l}80 \% \\
\text { CI-L }\end{array}$ & $\begin{array}{l}80 \% \\
\text { CI-U }\end{array}$ & $\%$ Variance \\
\hline Agreeableness & 59 & 18302 & .28 & .34 & .16 & .25 & .32 & .14 & .54 & $11.46 \%$ \\
\hline Emotion Perception & 23 & 3582 & .13 & .15 & .07 & .08 & .17 & .06 & .24 & $1.59 \%$ \\
\hline Emotion Understanding & 22 & 3374 & .09 & .12 & .04 & .05 & .13 & .06 & .17 & $3.21 \%$ \\
\hline Emotion Facilitation & 23 & 3582 & .13 & .17 & .02 & .10 & .16 & .13 & .20 & $3.69 \%$ \\
\hline Emotion Regulation & 22 & 3374 & .23 & .30 & .03 & .19 & .27 & .26 & .34 & $18.19 \%$ \\
\hline Conscientiousness & 60 & 18462 & .28 & .32 & .17 & .24 & .32 & .11 & .54 & $7.13 \%$ \\
\hline Emotion Perception & 23 & 3582 & .25 & .28 & .34 & .13 & .38 & -.16 & .71 & $0.47 \%$ \\
\hline Emotion Understanding & 22 & 3374 & .07 & .09 & .10 & .02 & .12 & -.04 & .21 & $1.03 \%$ \\
\hline Emotion Facilitation & 23 & 3582 & .09 & .11 & .11 & .04 & .14 & -.02 & .24 & $0.88 \%$ \\
\hline Emotion Regulation & 22 & 3374 & .13 & .16 & .09 & .08 & .18 & .04 & .28 & $3.20 \%$ \\
\hline Emotional Stability & 60 & 18416 & .33 & .39 & .24 & .28 & .38 & .08 & .69 & $7.29 \%$ \\
\hline Emotion Perception & 24 & 3696 & .11 & .12 & .02 & .07 & .14 & .10 & .14 & $1.70 \%$ \\
\hline Emotion Understanding & 22 & 3374 & .08 & .09 & .08 & .03 & .12 & -.01 & .19 & $1.61 \%$ \\
\hline Emotion Facilitation & 23 & 3582 & .09 & .11 & .03 & .05 & .13 & .07 & .15 & $1.89 \%$ \\
\hline Emotion Regulation & 22 & 3374 & .14 & .17 & .16 & .07 & .20 & -.04 & .38 & $1.98 \%$ \\
\hline Extraversion & 60 & 18450 & .28 & .33 & .27 & .22 & .34 & -.01 & 67 & $4.89 \%$ \\
\hline Emotion Perception & 24 & 3696 & .08 & .09 & .04 & .04 & .11 & .03 & .14 & $0.37 \%$ \\
\hline Emotion Understanding & 22 & 3374 & .06 & .07 & .11 & .01 & .11 & -.07 & .22 & $0.59 \%$ \\
\hline Emotion Facilitation & 23 & 3582 & .08 & .10 & .06 & .04 & .12 & .02 & .18 & $0.92 \%$ \\
\hline Emotion Regulation & 22 & 3374 & .14 & .18 & .09 & .10 & .19 & .06 & .29 & $3.71 \%$ \\
\hline Openness & 58 & 18170 & .23 & .27 & .20 & .19 & .28 & .02 & .53 & $5.78 \%$ \\
\hline Emotion Perception & 23 & 3582 & .06 & .07 & .10 & .01 & .11 & -.05 & .20 & $0.27 \%$ \\
\hline Emotion Understanding & 22 & 3374 & .14 & .18 & .14 & .07 & .19 & .00 & .36 & $3.22 \%$ \\
\hline Emotion Facilitation & 23 & 3582 & .08 & .10 & .14 & .02 & .13 & -.08 & .27 & $0.55 \%$ \\
\hline Emotion Regulation & 22 & 3374 & .12 & .16 & .13 & .07 & .18 & -.01 & .33 & $2.37 \%$ \\
\hline Cognitive Ability & 54 & 10519 & .13 & .16 & .18 & .09 & .17 & -.07 & .39 & $2.31 \%$ \\
\hline Emotion Perception & 20 & 4608 & .09 & .10 & .04 & .06 & .12 & .06 & .15 & $2.08 \%$ \\
\hline Emotion Understanding & 19 & 4479 & .31 & .39 & .15 & .09 & .22 & .20 & .59 & $14.03 \%$ \\
\hline Emotion Facilitation & 17 & 3869 & .15 & .18 & .14 & .25 & .38 & .00 & .37 & $2.85 \%$ \\
\hline Emotion Regulation & 18 & 4175 & .13 & .16 & .06 & .09 & .17 & .09 & .24 & $7.38 \%$ \\
\hline Job Performance & 17 & 2222 & .28 & .33 & .20 & .19 & .37 & .07 & .59 & $5.69 \%$ \\
\hline Emotion Perception & 4 & 253 & .14 & .16 & .14 & -.03 & .31 & -.02 & .33 & $0.27 \%$ \\
\hline Emotion Understanding & 4 & 253 & .17 & .20 & .07 & .04 & .31 & .10 & .29 & $2.39 \%$ \\
\hline Emotion Facilitation & 3 & 191 & .17 & .20 & .00 & .09 & .26 & .20 & .20 & $4.04 \%$ \\
\hline Emotion Regulation & 4 & 253 & .18 & .21 & .20 & -.03 & .38 & -.04 & .46 & $0.05 \%$ \\
\hline
\end{tabular}

Note. $k$ : number of effect sizes in the meta-analysis; $N$ : total sample size in the meta-analysis; $r$ : samplesize weighted mean correlation; $\rho$ : correlation corrected for attenuation; SD $\rho$ : standard deviation of corrected correlation; 95\% CI-U/L: upper/lower bound of confidence interval; $80 \% \mathrm{CI}-\mathrm{U} / \mathrm{L}$; upper/lower bound of credibility interval; $\%$ variance: percent of variance accounted for by artifacts. 
Table 9

Meta-Analytic Results for Construct-Method Pairings of Emotional Intelligence, Big Five Personality Traits, Cognitive Ability, and Job Performance

\begin{tabular}{|c|c|c|c|c|c|c|c|c|c|c|}
\hline & $k$ & $N$ & $r$ & $\rho$ & $\mathrm{SD} \rho$ & $\begin{array}{l}95 \% \\
\text { CI-L }\end{array}$ & $\begin{array}{l}95 \% \\
\text { CI-U }\end{array}$ & $\begin{array}{l}80 \% \\
\text { CI-L }\end{array}$ & $\begin{array}{l}80 \% \\
\text { CI-U }\end{array}$ & $\begin{array}{c}\% \\
\text { Variance }\end{array}$ \\
\hline \multicolumn{11}{|l|}{ Agreeableness } \\
\hline Self-report mixed EI & 30 & 5386 & .36 & .43 & .13 & .31 & .41 & .27 & .59 & $28.39 \%$ \\
\hline Self-report ability EI & 26 & 8479 & .26 & .31 & .13 & .21 & .30 & .14 & .48 & $9.48 \%$ \\
\hline Performance-based EI & 23 & 4287 & .25 & .29 & .15 & .18 & .31 & .09 & .48 & $7.22 \%$ \\
\hline \multicolumn{11}{|l|}{ Conscientiousness } \\
\hline Self-report mixed EI & 31 & 5591 & .33 & .38 & .17 & .27 & .39 & .16 & .64 & $12.14 \%$ \\
\hline Self-report ability EI & 27 & 8566 & .32 & .38 & .10 & .28 & .36 & .26 & .51 & $18.27 \%$ \\
\hline Performance-based EI & 21 & 4155 & .12 & .13 & .10 & .07 & .16 & .00 & .26 & $1.81 \%$ \\
\hline \multicolumn{11}{|l|}{ Emotional Stability } \\
\hline Self-report mixed EI & 30 & 5386 & .45 & .53 & .22 & .38 & .53 & .25 & .81 & $22.01 \%$ \\
\hline Self-report ability EI & 26 & 8479 & .34 & .40 & .14 & .28 & .39 & .22 & .59 & $12.56 \%$ \\
\hline Performance-based EI & 22 & 4401 & .17 & .20 & .26 & .08 & .27 & -.13 & .54 & $1.15 \%$ \\
\hline \multicolumn{11}{|l|}{ Extraversion } \\
\hline Self-report mixed EI & 30 & 5552 & .40 & .46 & .13 & .35 & .45 & .29 & .63 & $28.07 \%$ \\
\hline Self-report ability EI & 26 & 8479 & .27 & .32 & .28 & .18 & .37 & -.04 & .69 & $5.88 \%$ \\
\hline Performance-based EI & 23 & 4269 & .15 & .18 & .26 & .05 & .24 & -.15 & .51 & $0.67 \%$ \\
\hline \multicolumn{11}{|l|}{ Openness } \\
\hline Self-report mixed EI & 30 & 5386 & .26 & .29 & .20 & .19 & .32 & .04 & .55 & $8.94 \%$ \\
\hline Self-report ability EI & 26 & 8479 & .24 & .29 & .19 & .18 & .31 & .05 & .54 & $5.60 \%$ \\
\hline Performance-based EI & 21 & 4155 & .18 & .21 & .18 & .11 & .25 & -.01 & .44 & $3.19 \%$ \\
\hline \multicolumn{11}{|l|}{ Cognitive Ability } \\
\hline Self-report mixed EI & 19 & 2880 & .09 & .11 & .17 & .03 & .15 & -.10 & .33 & $2.54 \%$ \\
\hline Self-report ability EI & 15 & 2056 & .00 & .00 & .07 & -.05 & .05 & -.14 & .12 & $0.00 \%$ \\
\hline Performance-based EI & 27 & 5436 & .22 & .28 & .15 & .17 & .27 & .08 & .48 & $7.58 \%$ \\
\hline \multicolumn{11}{|l|}{ Job Performance } \\
\hline Self-report mixed EI & 7 & 1040 & .38 & .43 & .22 & .23 & .54 & .18 & .73 & $17.61 \%$ \\
\hline Self-report ability EI & 5 & 604 & .16 & .19 & .09 & .07 & .27 & .07 & .30 & $1.24 \%$ \\
\hline Performance-based EI & 5 & 516 & .25 & .28 & .05 & .16 & .35 & .21 & .34 & $0.49 \%$ \\
\hline
\end{tabular}

Note. $k$ : number of effect sizes in the meta-analysis; $N$ : total sample size in the meta-analysis; $r$ : samplesize weighted mean correlation; $\rho$ : correlation corrected for attenuation; SD $\rho$ : standard deviation of corrected correlation; 95\% CI-U/L: upper/lower bound of confidence interval; $80 \% \mathrm{CI}-\mathrm{U} / \mathrm{L}$; upper/lower bound of credibility interval; \% variance: percent of variance accounted for by artifacts.

variance accounted for by artifacts for each of the EI and Big Five estimates is quite low $(4.89 \%-11.46 \%)$, indicating that moderators for each of these relationships may indeed be present.

Results concerning one potential moderator, EI dimensions, are also displayed in 
Table 8. Meta-analytic estimates of EI dimensions and Big Five personality traits are based on as few as 22 effect sizes and as many as 24 effect sizes, with total sample size ranging from 3,374 to 3,696. Among the four dimensions of EI, Emotion Perception had the strongest relationship with Conscientiousness $(\rho=.28)$, Emotion Understanding had the strongest relationship with Openness $(\rho=.18)$, Emotion Facilitation had the strongest relationship with Agreeableness $(\rho=.17)$ and Emotion Regulation also had the strongest relationship with Agreeableness $(\rho=.30)$. In general, Emotion Regulation showed a stronger relationship to several of the Big Five factors (Agreeableness, $\rho=.30$; Emotional Stability, $\rho=.17$; and Extraversion, $\rho=.18$ ) than did the remaining EI dimensions. Upon examining whether EI dimensions serve as a moderator of the EI-Big Five relationship, the magnitude of the meta-analytic estimates indicates that EI dimensions may act as a moderator.

Results of a second potential moderator, construct-method pairing of the EI measure used, are presented in Table 9. Table 9 splits each EI-Big Five relationship into three possible construct-method pairings: self-report mixed EI, self-report ability EI, and performance-based EI, with the number of effect sizes varying from as few as 21 to as many as 31 , and the total sample size within the moderator analysis ranging from 4,155 to 8,566 . Results consistently demonstrate that the construct-method pairing with the strongest relationship to Big Five personality traits is self-report mixed EI measures, whose relationship with Big Five personality traits ranges from $\rho=.29$ (Openness) to $\rho$ $=.53$ (Emotional Stability). Performance-based EI consistently has the smallest relationship with Big Five traits, ranging from $\rho=.13$ (Conscientiousness) to $\rho=.29$ 
(Agreeableness). In addition, the percent of variance accounted for by artifacts among construct-method pairings is larger than for the overall EI - Big Five relationships, suggesting that construct-method pairing serves as a moderator of the relationship between EI and each of the Big Five personality traits.

Emotional Intelligence and Cognitive Ability Meta-Analytic Estimates. The results of a meta-analysis of EI and cognitive ability are presented in Table 8. Table 8 demonstrates that the true score correlation between overall EI and cognitive ability is .16 , which is based on 54 effect sizes and a total sample size of 10,519 . The credibility interval of this estimate includes zero, the standard deviation of this estimate is .18, and the amount of variance due to artifacts is relatively low (2.31\%), indicating the likely presence of moderators.

Tables 8 and 9 show the results of the moderator analyses for the relationship between EI and cognitive ability. Table 8 investigates the potential for EI dimensions to serve as a moderator of this relationship, and results show Emotional Understanding exhibits the strongest relationship with cognitive ability $(\rho=.39)$, followed by Emotion Facilitation $(\rho=.18)$. Emotion Regulation and Emotion Perception have the lowest relationship with cognitive ability ( $\rho=.16$ and $\rho=.10$, respectively). The variance accounted for by artifacts for EI dimension is larger than that of overall EI and cognitive ability, suggesting that EI dimensions is in fact a moderator of the EI - cognitive ability relationship. Moreover, difference in magnitude of the EI dimension estimates strengthens the support for EI dimensions as a moderator of the relationship between EI and cognitive ability. 
Table 9 divides the overall EI relationship with Big Five into self-report mixed EI, self-report ability EI, and performance-based EI in order to investigate the constructmethod pairing of EI measures as a moderator of EI's relationship with cognitive ability. Results show that performance-based EI has the strongest relationship with cognitive ability $(\rho=.28)$, followed by self-report mixed EI $(\rho=.11)$. Self-report ability EI showed no relationship with cognitive ability $(\rho=.00)$. The amount of variance accounted for by artifacts within construct-method pairings is more than that of the overall EI relationship with cognitive ability, suggesting that construct-method pairing is another moderator of the EI and cognitive ability relationship.

Emotional Intelligence and Job Performance Meta-Analytic Estimates. Results regarding the relationship between EI and job performance are presented in Tables 8 and 9. The relationship between overall EI and job performance is based on 17 effect sizes and 2,222 individuals, with an estimated true score correlation of .33. Although the credibility interval of this relationship does not include zero, the amount of variance accounted by artifacts is low (5.69\%), and thus, the presence of moderators is likely.

Table 8 presents results on dimensions of EI as a moderator of EI's relationship with job performance. These results are based on 3 effect sizes and 191 individuals. Although these results are tentative (based on the smaller sample size), it appears that Emotion Regulation has the strongest relationship with job performance $(\rho=.29)$, followed by Emotion Understanding ( $\rho=.28$ ), Emotion Perception $(\rho=.26)$, and finally, Emotion Facilitation $(\rho=.20)$. This accounts for slightly more variance due to artifacts 
than overall EI, tentatively suggesting that EI dimensions serve as a moderator of this relationship.

A second set of moderator analyses for the relationship between EI and job performance is presented in Table 9, where EI is divided into construct-method pairings. Results presented here are based on 5-7 effect sizes with a total sample size of 516-1040 individuals, and they demonstrate that self-report mixed EI has by far the strongest relationship with job performance $(\rho=.43)$, followed by performance-based EI $(\rho=.28)$. Self-report ability EI, on the other hand, shows the weakest relationship with job performance $(\rho=.19)$. The variance of these meta-analytic estimates across constructmethod pairings as well as the increase in percent variance due to artifacts indicates that construct-method pairing does moderate the relationship between EI and job performance.

Results of Hypothesis Tests

Results testing the fit of the cascading model of EI are presented in Figure 2. The fit statistics for the full model with nine degrees of freedom are: $\chi^{2}=11.14$, SRMR $=$ $.05, \mathrm{RMSEA}=.03, \mathrm{GFI}=.98, \mathrm{NNFI}=.98, \mathrm{CFI}=.99$. All of the fit statistics are in the acceptable ranges (Hu \& Bentler, 1999). All of the hypothesized paths were significant and in the expected direction except for the paths from Emotional Stability to Emotion Regulation $(\beta=.09, \mathrm{~ns})$ and Emotion Stability to Job Performance $(\beta=-.01, \mathrm{~ns})$.

Results of Hypotheses 1 and 2 appear in Table 10. As seen in Table 10, performance-based, self-report ability, and self-report mixed EI measures demonstrate incremental validity above a composite of Big Five personality traits 


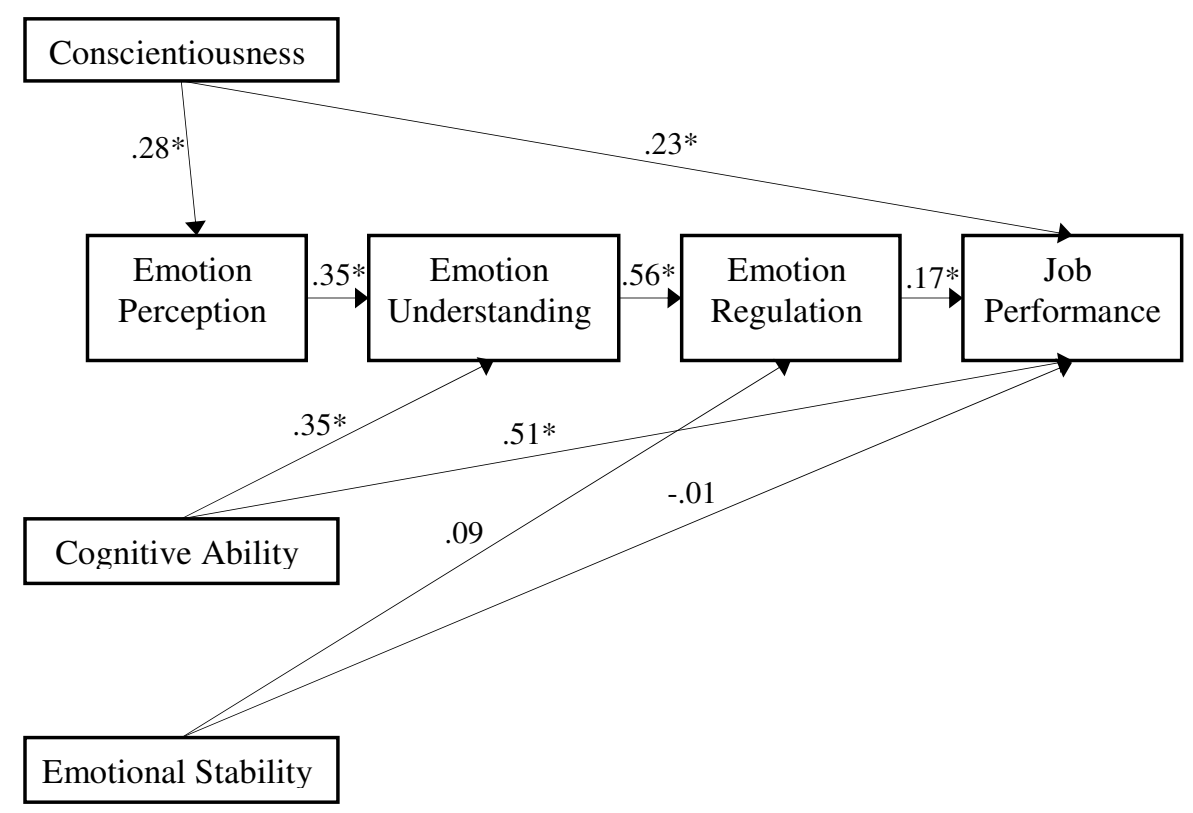

Figure 2. Mediated model of emotional intelligence dimensions and job performance with path coefficients. ${ }^{*} \mathrm{p}<.05$ Path coefficients are completely standardized; fit indices for the above model are as follows: $\chi^{2}(9 \mathrm{df})=11.14 ; \mathrm{RMSEA}=.03 ; \mathrm{NNFI}=.983 ; \mathrm{CFI}=.99 ; \mathrm{SRMR}=.05$.

$\left(\Delta R_{\text {Performance-Based EI }}^{2}=6.3 \% ; \Delta R_{\text {Self-report Ability EI }}^{2}=1.5 \% ; \Delta R_{\text {Self-report Mixed EI }}^{2}=14.5 \% ; p<\right.$

.05). These results support Hypothesis 1, in which we predicted that all construct-method EI pairings would predict significant unique variance in job performance above Big Five personality traits. Regarding Hypothesis 2, we find that performance-based EI measures, self-report ability EI measures, and self-report mixed EI measures all have incremental value for predicting performance over and above cognitive ability $\left(\Delta R_{\text {Perfmorance-Based EI }}^{2}=\right.$ $\left.3.4 \% ; \Delta R_{\text {Self-report Ability EI }}^{2}=3.3 \% ; \Delta R_{\text {Self-report Mixed EI }}^{2}=12.6 \% ; p>.05\right)$. Hypothesis 2 predicted that self-report mixed EI measures would predict significant unique variance above cognitive ability, which is supported by these results. Further, performance- based 
Table 10

Incremental Validity and Adverse Impact Reduction for Emotional Intelligence Construct-Method Pairings

\begin{tabular}{|c|c|c|c|c|c|c|c|c|c|c|c|}
\hline \multirow[b]{2}{*}{ Variable } & \multicolumn{11}{|c|}{ Models } \\
\hline & $\mathrm{P}$ & I & II & III & IV & $\mathrm{V}$ & VI & $\mathrm{P} \& \mathrm{C}$ & VII & VIII & IX \\
\hline \multicolumn{12}{|l|}{ Big Five Personality } \\
\hline Agreeableness & .01 & -.04 & .00 & -.05 & & & & .03 & -.01 & .02 & -.03 \\
\hline Conscientiousness & $.15^{*}$ & $.15^{*}$ & $.12 *$ & $.08 *$ & & & & $.18 *$ & $.18^{*}$ & $.15^{*}$ & $.11 *$ \\
\hline Emotional Stability & .02 & .01 & -.01 & $-.11 *$ & & & & -.01 & -.02 & -.04 & $-.14 *$ \\
\hline Extraversion & .05 & .03 & .03 & $-.07 *$ & & & & $.06 *$ & .05 & .04 & -.05 \\
\hline Openness & -.01 & -.04 & -.02 & -.04 & & & & $-.09 *$ & $-.10^{*}$ & $-.11^{*}$ & $-.12 *$ \\
\hline Cognitive Ability & & & & & $.37 *$ & $.41 *$ & $.38 *$ & $.43 *$ & $.40 *$ & $.44 *$ & $.41 *$ \\
\hline \multicolumn{12}{|l|}{ Emotional Intelligence } \\
\hline Performance-Based & & $.26 *$ & & & $.19 *$ & & & & $.18^{*}$ & & \\
\hline Self-Report Ability & & & $.14 *$ & & & $.18^{*}$ & & & & $.16^{*}$ & \\
\hline Self-Report Mixed & & & & $.47 *$ & & & $.36^{*}$ & & & & $.44 *$ \\
\hline$R^{2}$ & $.032 *$ & $.095^{*}$ & $.047^{*}$ & $.177^{*}$ & $.202 *$ & $.201 *$ & $.294 *$ & $.210^{*}$ & $.238^{*}$ & $.230 *$ & $.335^{*}$ \\
\hline Adjusted $\boldsymbol{R}^{2}$ & $.038 *$ & $.084 *$ & $.038 *$ & $.172 *$ & $.199 *$ & $.198 *$ & $.292 *$ & $.206^{*}$ & $.227 *$ & $.221 *$ & $.330 *$ \\
\hline Change in $\boldsymbol{R}^{2}$ & & $.063^{*}$ & $.015^{*}$ & $.145^{*}$ & $.034 *$ & $.033 *$ & $.126^{*}$ & & $.028^{*}$ & $.020 *$ & $.125^{*}$ \\
\hline \multicolumn{11}{|l|}{ Black-White Subgroup d } & -.32 \\
\hline $\begin{array}{l}\text { Black-White Subgroup d } \\
\text { for composite with EI }\end{array}$ & & -.13 & -.04 & -.14 & -.43 & -.36 & -.58 & & -.30 & -.23 & -.31 \\
\hline \multicolumn{12}{|l|}{ Change in Black-White } \\
\hline Subgroup d & & -.02 & .07 & -.03 & .29 & .36 & .14 & & .02 & .09 & .01 \\
\hline \multicolumn{12}{|l|}{ Female-Male Subgroup d } \\
\hline $\begin{array}{l}\text { Female-Male Subgroup d } \\
\text { for composite with EI }\end{array}$ & & .16 & .02 & .02 & .16 & .02 & .02 & & .07 & -.06 & -.05 \\
\hline \multicolumn{12}{|l|}{ Change in Female-Male } \\
\hline Subgroup d & & .14 & .00 & .00 & .46 & .32 & .32 & & .14 & .01 & .02 \\
\hline
\end{tabular}

Note. $* p<.05$; Standardized regression coefficients; Model $\mathrm{P}=$ personality; Model $\mathrm{P} \& \mathrm{C}=$ personality and cognitive ability. Negative subgroup $d$ values indicate Whites scoring higher than Blacks and males scoring higher than females. Negative "change in subgroup $d$ " indicates adverse impact potential has worsened.

EI, self-report ability EI, and self-report mixed EI predict job performance over and above a composite of cognitive ability and each of the Big Five measures, although the incremental variance accounted for is very small in the cases of performance-based 
EI and self-reported ability-based EI ( $\Delta R_{\text {Performance-based EI }}^{2}=2.8 \% ; \Delta R_{\text {Self-report Ability EI }}^{2}=$ $\left.2.0 \% ; \Delta R_{\text {Self-report Mixed EI }}^{2}=12.5 \% ; p<.05\right)$.

In reference to adverse impact potential (i.e., subgroup $d$ ), we found that all construct-method pairings of EI exhibited smaller Black-White and female-male subgroup $d$ values when compared to cognitive ability. (Subgroup $d$ values are shown in Table 6.) Regarding race differences, self-report ability measures showed a standardized mean difference of .21 with Blacks scoring higher than Whites, while self-report mixed EI measures and performance-based measures showed $d$ values with Whites scoring higher than Blacks (self-report mixed: $d=-.22$; performance-based ability: $d=-.11$ ). Because each of these $d$ values is smaller than that of cognitive ability $(d=-.72)$, Hypothesis $3 \mathrm{a}$ is supported. Regarding sex differences in EI in that self-report ability EI measures show almost no female-male differences $(d=.01)$, and a similar lack of sex differences are also found in self-report mixed EI measures $(d=.02)$. Performance-based EI measures, however, show larger sex differences with females scoring higher than males $(d=.52)$. In comparison to sex differences on cognitive ability $(d=.30)$, selfreport ability and self-report mixed EI measures show smaller subgroup $d$ values, while performance-based ability EI measures show larger subgroup $d$ values. Therefore, Hypothesis $3 b$ is only partially supported, which predicted that all three constructmethod pairings would results in a smaller subgroup $d$ than cognitive ability.

Additional analyses were conducted to investigate the potential for a reduction in adverse impact when a composite is constructed with EI and Big Five personality traits and/or cognitive ability. Results are shown in Table 10. Regarding race differences, we 
found self-report ability EI measures to exhibit the largest reduction in Black-White mean differences when compared to Big Five personality traits, cognitive ability, or both. Compared to a composite of the Big Five traits, a composite of self-report ability EI measures and Big Five personality traits reduced Black-White differences by .07 . Compared to a cognitive test alone, a composite of self-report ability EI measures and cognitive ability reduced Black-White subgroup $d$ by .36. Finally, compared to a composite of cognitive ability with Big Five traits, the addition of self-report ability EI measures lowered Black-White differences by .09.

Regarding performance-based EI measures, a composite of Big Five traits results in a smaller subgroup $d(-.11)$ than a composite of Big Five traits and performance-based EI $(d=-.13)$. Meanwhile, performance-based EI measures did reduce Black-White subgroup $d$ by .29 compared to a cognitive test alone. Finally, performance-based EI measures reduced Black-White $d$ by only .02 compared to a composite of Big Five traits and cognitive ability.

Similar results are found for self-report mixed measures. Specifically, self-report mixed measures of EI increase Black-White subgroup $d$ by .03 over a composite of Big Five personality traits. Self-report mixed measures reduce Black-White subgroup $d$ by .14 when compared to cognitive ability measures alone. Additionally, self-report mixed measures reduced Black-White subgroup $d$ by .01 over a composite of both Big Five traits and cognitive ability.

Results regarding potential for adverse impact against females show that all three construct-method pairings reduced the subgroup $d$ between females and males by as 
much as .46 for performance-based measures and as little as .32 for self-report ability and mixed measures of EI when compared to cognitive ability measures alone. In addition, performance-based measures reduced the subgroup $d$ between females and males by .14 when a composite of personality and EI is constructed, and also by .14 when a composite of personality, cognitive ability, and EI is constructed. Meanwhile, compared to a composite of Big Five personality, self-report ability and self-report mixed EI measures show no change in subgroup $d$ (.00 for self-report mixed and .00 for self-report ability). Self-reports (both ability and mixed) also show almost no change in subgroup $d$ when compared to a composite of personality and cognitive ability (.01 for self-report ability and .02 for self-report mixed).

In sum, we find support for Hypothesis $3 \mathrm{a}$ and partial support for Hypothesis $3 \mathrm{~b}$ and we note that all three construct-method EI pairings result in a reduced potential for adverse impact against both Blacks and females when compared to a cognitive ability test alone. 


\section{DISCUSSION AND CONCLUSIONS}

The current paper sought to address proponents' claims that EI is highly predictive of job performance, and also address critics' claims that EI is redundant with the well-established constructs of Big Five personality traits and cognitive ability. We proposed and then empirically evaluated a theoretically-driven model of EI and job performance. This model of EI proposed a sequential (causal chain) relationship among the three dimensions of EI and job performance, and further included personality traits and cognitive ability as important antecedents in the EI processes that affect job performance. Finally, the current paper also contributed to EI research by evaluating the potential for EI measures to incrementally predict job performance and reduce adverse impact potential against Blacks and females in a selection setting. The results of this study are discussed below, as well as a presentation of strengths and limitations of the paper and directions for future research.

\section{Discussion of Meta-Analyses}

Meta-analytic estimates of the correlation between EI and Big Five personality traits show that EI has the strongest relationship with Emotional Stability $(\rho=.39)$ and the weakest relationship with Extraversion $(\rho=.27)$. This is consistent with previous suggestions that EI has the strongest connection to Emotional Stability (Conte \& Dean, 2006; Eysenck, 1998, Landy, 2005), although it is simultaneously inconsistent with some scholars' suspicions that EI would also be redundant with Extraversion (e.g., Conte \& Dean, 2006; Landy, 2005). Overall EI was also related to cognitive ability $(\rho=.16)$, although not to the same extent that overall EI was related to Big Five personality traits. 
Finally, the attenuation-corrected correlation between EI and job performance was .33, confirming that EI is positively related to job performance. However, in interpreting the true score correlations of overall EI with Big Five personality, cognitive ability, and job performance, we note that these meta-analytic estimates are of limited use because overall EI includes two very different conceptualizations of EI (ability and mixed), which previous evidence has shown to be two relatively distinct constructs (Van Rooy et al., 2005). As such, we report estimates of overall EI, but warn against their interpretation as evidence of the redundancy (or lack thereof) of emotional intelligence as a construct. That is, EI is a collection of constructs, and these various constructs have a particular form of interrelationship as they predict job performance.

Perhaps more useful in interpreting the utility of EI as a construct is the discussion of results in terms of the relationship between varying construct-method pairings of EI and relevant variables. Three construct-method pairings were investigated in the current paper: performance-based ability, self-report ability, and self-report mixed. Of the three construct-method pairings, self-report mixed EI showed the strongest relationship to Big Five personality traits, with correlations corrected for attenuation ranging from .29 with Openness to .53 with Emotional Stability. These results appear to support critics' claims that mixed EI exhibits significant overlap with Big Five personality traits (Daus \& Ashkanasy, 2003). Upon examining the items of a popular mixed-based measure of EI, the EQ-i (Bar-On, 1997), it comes as no surprise that mixed EI shows a strong relationship with Emotional Stability. For example, the following items from the EQ-i (Bar-On, 1997) appear to reflect the element of anxiety and worry 
that is characteristic of Emotional Stability: "I feel that it's hard for me to control my anxiety", "I can handle stress without getting too nervous", and "I get anxious". Selfreports of mixed EI were also shown to have a weak relationship with cognitive ability $(\rho=.11)$. This is consistent with the expectations of mixed models of EI in that mixed models measure a combination of intellect, personality, and affect, thus reducing their relationship with cognitive ability by tapping into constructs other than intelligence. Moreover, although mixed-based measures of EI purport to measure an emotional intelligence, we suggest that because mixed-based measures only employ self-report methods at this time, it is more likely that these measures reflect self-perceptions of intellect rather than actual intellect, as reflected in the low correlations between selfreport mixed measures and cognitive ability. Finally, of the three construct-method pairings investigated in the current paper, self-report measures of mixed EI showed the strongest relationship with job performance $(\rho=.43)$. An investigation of the incremental validity of mixed EI (self-report) shows that mixed EI explains an additional $12.5 \%$ of the variance in job performance over and above Big Five traits and cognitive ability. While this is a considerable contribution to the prediction of job performance, the contribution lacks a theoretical basis. That is, theory linking mixed models of EI to performance is underdeveloped, and the construct(s) labeled mixed EI is not clearly defined or conceptualized. In addition to the considerable amount of unique variance in job performance predicted by mixed EI, results show it may also reduce the potential for adverse impact against Blacks and females when used in combination with cognitive ability (reducing Black-White subgroup $d$ by .14 and male-female subgroup $d$ by .32) 
Overall, measures of EI that assess mixed models appear to offer two contributions to selection systems in organizations: first, these measures predict considerable unique variance in job performance, and second, these measures can reduce the potential for adverse impact against Blacks and females when used with a measure of cognitive ability.

In comparison, the meta-analytic evidence presented here shows that EI measures based on the ability model of EI have little incremental validity over Big Five traits and cognitive ability. Specifically, self-report measures of ability EI only offer $2.0 \%$ of the explained variance in job performance above personality and cognitive ability, and performance-based measures of ability EI also contribute a mere $2.8 \%$ of unique variance in job performance. This is likely driven by the weaker relationship between ability-based measures of EI and job performance $(\rho=.28$ for performance-based, $\rho=$ .19 for self-reported ability) in comparison to mixed-based measures. Despite the limited contribution of ability-based EI in the prediction of job performance, results of the current meta-analysis show that ability-based EI can reduce the potential for adverse impact against both Blacks and females when used in combination with a measure of cognitive ability.

Thus, both ability-based EI measures and mixed-based EI measures may have utility in selection systems where they can be used in combination with measures of cognitive ability to maintain prediction of performance (i.e., while adding ability EI increases performance prediction by a negligible amount, it does not hinder performance 
prediction-incremental $\mathrm{R}^{2}$ is positive, not negative) or enhance prediction of performance while reducing the potential for adverse impact against Blacks and females. In comparing the methods of measuring ability-based EI, although both methods produce nearly equal incremental validity over personality and cognitive ability, one method appears to provide additional benefits in the reduction of adverse impact: selfreport measures of ability-based EI. Specifically, self-report measures of ability EI models offer a greater reduction in potential for adverse impact against Blacks and females when compared to performance-based measures of ability EI. However, the use of self-reports in measuring ability warrants caution. A self-report of ability may be susceptible to socially desirable responding (Paulhus, 1984), and self-reports of ability have been criticized for the inherent paradox in asking someone to report their own levels of intelligence (Matthews, Emo, Roberts, \& Zeidner, 2006). In addition, we express concern that although self-report ability EI measures are purported measures of ability, they actually had a corrected correlation of .00 with cognitive ability. A closer look at items on self-report measures of ability EI raises questions about the extent to which an actual ability is being measured. For example, one of the 16 items on the WLEIS (Wong \& Law, 2002; Emotion Facilitation facet) is, "I always set goals for myself and then try my best to achieve them". This item-which is similar to three additional WLEIS items - appears to address motivation rather than ability. Because of items like this on self-reports of ability EI, we propose that self-reports of ability EI are similar to mixed-based measures of EI in that research has yet to confirm exactly what constructs are being measured with these scales. 
Finally, the current meta-analysis was used to test a model of EI based on theory relating EI subdimensions (as measured with performance-based scales) to job performance (see Figure 1). The cascading model of EI presented the dimensions of ability-based EI in a sequential manner such that emotion perception precipitates emotion understanding, which in turn leads to emotion regulation (the key element in the model), which in turn influences job performance. Moreover, the model specifies these three dimensions of EI as partial mechanisms by which Big Five personality traits and cognitive ability affect performance (Figure 1). Results show that the cascading model of EI presented here had acceptable fit, providing empirically-supported theory regarding the relationships between EI dimensions and job performance.

\section{Strengths and Limitations}

The current paper offers several contributions to research on emotional intelligence. First, this meta-analysis presents and empirically tests a theoretical model of EI dimensions and job performance. At this point, no previous work has sought to elaborate on the theoretical linkage between emotional intelligence and job performance, which has likely contributed to skepticism regarding the validity of emotional intelligence as a construct that is useful in organizations. Moreover, our theory regarding why emotional intelligence should predict job performance points to a particular dimension of EI that drives EI's relationship with job performance: emotion regulation. In support of our belief that emotion regulation is the key element of EI, previous research on emotion regulation has elaborated on the utility of emotion regulation in organizational contexts, as well as theory regarding how the process of emotion 
regulation occurs. Gross (1998) put forth a model of several emotion regulation processes, including selection of the situation, modification of the situation, deployment of attention, change of cognitions, and modulation of responses, all of which are applicable to organizational settings. Work by Beal and colleagues $(2005,2006)$ has also discussed the role of emotion regulation in job performance, including additional strategies for emotion regulation not discussed by Gross (1998). Specifically, Beal et al. (2005) present a model of episodic processes and their affective influences on performance. In this model, these authors discuss how emotion regulation processes, cognitive demands, and attentional pull of the task affect short-term performance episodes. In addition, Beal, Trougakos, Weiss, and Green (2006) highlight the importance of emotion regulation on the job through the examination of emotional labor. Emotional labor can refer to "instances of emotion regulation, jobs that require high levels of emotion regulation, or jobs for which emotion regulation is necessary and frequent" (Beal et al., 2006, p. 1053), and support for this concept as well as the emotion regulation processes presented in Beal and colleagues' $(2005,2006)$ work and Gross' (1998) research help solidify the theoretical and empirical link between emotion regulation and job performance that is presented in the current paper.

Second, the current meta-analytic estimates provide empirical evidence that can be used to evaluate recent claims of EI's utility in job performance. Although two metaanalyses of emotional intelligence exist in previous work (Van Rooy \& Viswesvaran, 2004; Van Rooy et al. 2005), we believe the current meta-analysis offers additional contributions to the discussion of EI. In particular, both previous meta-analyses (Van 
Rooy \& Viswesvaran, 2004; Van Rooy et al., 2005) were based on 60 or fewer effect sizes, while the current meta-analysis is draws on 106 effect sizes, and a total sample size of nearly 30,000 individuals. Not only was a newer meta-analysis needed to account for the recent surge in research on EI, but the current paper also utilizes stricter inclusion criteria for job performance measures such that job performance includes only performance on the job as rated by a supervisor, which enhances the accuracy of the operational validities presented here. Moreover, the current paper addresses a constructmethod issue present in the literature on EI by presenting meta-analytic estimates of three construct-method pairings, rather than the two constructs (ability and mixed) that have been evaluated in previous meta-analytic work (Van Rooy \& Viswesvaran, 2004; Van Rooy et al., 2005). Finally, the current meta-analysis has addressed Van Rooy et al.'s (2005) call for future research to investigate meta-analytic estimates concerning each dimension of EI and its relationship to Big Five personality traits, cognitive ability, and job performance. The current paper presents estimates of each of these relationships in order to examine not only the relationship between overall EI and previously established constructs, but the relationship between EI dimensions and these constructs, as well.

Despite the strengths of the current paper, limitations also exist. First, the empirical evaluation of the cascading model of EI presented here is based on a relatively small sample size. As such, we warn against concluding that the cascading model of EI represents a definitive model of how EI affects job performance, although the theoretical basis of this model and the tentative support for the model shown here offer promise for 
additional support in the future. Additionally, the cascading model of EI includes only three of the four dimensions of EI due to the conceptual redundancy between Emotion Facilitation and Emotion Regulation, as well as previous research findings that factor analytic models of EI have improved fit when Emotion Facilitation is not included (Gignac, 2005; Palmer et al., 2005; Rossen et al., 2008) Therefore, the cascading model of EI may have neglected some of the construct space of EI as originally conceptualized by Mayer and Salovey (1997). Future research would benefit from clarifying the dimension of Emotion Facilitation that was not included in the cascading model of EI in order for theory relating EI with job performance to capture the entire construct domain of emotional competencies.

Second, although the results of the current meta-analysis show the potential utility of self-report measures of mixed EI models, the lack of conceptual clarity in these models leads us to caution against their application in organizations without further investigation of the constructs that these measures assess. Self-report measures of ability EI suffer from similar problems in that not all of the items on these measures appear to assess a true ability. Therefore, we caution against applying the current results to organizational settings without knowledge of the constructs assessed by these self-report measures.

Directions for Future Research

As a result of the current paper and the limitations previously mentioned, several areas of research are worth further consideration. Most notably, future work on the construct-related validity of both self-report mixed and self-report ability measures is 
necessary for the advancement of EI as a viable construct. This would involve an indepth examination of the relationship between these measures and established constructs other than personality and cognitive ability, such as self-efficacy and motivation. Although we have established that the mixed model of EI is not redundant with personality traits or cognitive ability, its redundancy with other well-established constructs is worthy of investigation.

Future research would also benefit from examining the type of job as a moderator of the relationship between EI and job performance. It is expected that jobs requiring large amounts of emotion regulation would show the strongest relationship between EI and job performance. Because the current results show EI may be useful as a selection tool, an analysis of which jobs would benefit the most from using EI as a selection tool is warranted.

Finally, EI research would also benefit from evaluating the widespread application of EI training programs and their relationship with job performance. Over recent years, the EI training programs have found a home in many organizations [e.g. American Express, AT\&T, Pfizer, Deluxe, Franklin Templeton Investments, the U.S. Army and Navy, Nextel, Oracle, Johnson \& Johnson, United Auto Workers, Xerox (Schmit, 2006)], although no meta-analysis has sought to address the utility of these training programs. Although the current meta-analysis sought to address many claims of EI's utility, Goleman's (1995) claim that EI can be trained is also in need of empirical evaluation in order for the academic wing of EI research to catch up to the commercial explosion of EI applications in organizations. 


\section{Conclusion}

In conclusion, the findings of the current study appear to offer a mixed answer to the question, "Is emotional intelligence worthwhile?". Specifically, the answer is a familiar one to questions asked in social sciences, which is, emotional intelligence is worth additional research. Ability-based measures appear to have practical utility for reducing adverse impact potential when used in combination with cognitive ability measures, although the expense of using proprietary performance-based measures and their limited incremental validity may dampen their utility in organizations. However, additional research may show that these measures demonstrate more incremental validity in some occupations than others, which would provide evidence of their incremental validity that was not found in the current study. For mixed models, the utility of EI appears promising, due to the considerable amount of incremental validity and shown in the current study as well as the potential for these measures to reduce adverse impact against Blacks and females, although more research regarding the constructs assessed by these measures is necessary. 


\section{REFERENCES}

Ackerman, P. L. (1996). A correlational analysis of skill specificity: Learning, abilities, and individual differences. Journal of Experimental Psychology: Learning, Memory, and Cognition, 16, 883-901.

ACT, Inc. (2002). Test preparation reference manual. Iowa City, IA: ACT.

Albert, J. (1998). Cognitive measures: Comparison of the Canadian Forces Aptitude Test (CFAT), Raven's Progressive Matrices and the Wonderlic Personnel Test (Technical Note (98-5)). Ottawa, Canada: Director Human Resources Research and Evaluation.

Alfolabi, O. A., \& Ehigie, B. O. (2005). Psychological diversity and team interaction processes: A study of oil-drilling work teams in Nigeria. Team Performance Management, 11, 280-301.

Amthauer, R., Brocke, B., Liepmann, D., \& Beauducel, A. (2001). Intelligenz Strukture Test 2000. Göttingen, Germany: Hogrefe.

Arthur, W. Jr., \& Villado, A. J. (2008). The importance of distinguishing between constructs and methods when comparing predictors in personnel selection research and practice. Journal of Applied Psychology, 93, 435-442.

Baddeley, A. (1968). A 3 min reasoning test based on grammatical transformation. Psychonomic Science, 10, 341-342.

Barrick M. R., \& Mount, M. K. (2005). Yes, personality matters: Moving on to more important matters. Human Performance, 18, 359-372. 
Barrick, M. R., Mount, M. K., \& Judge, T. A. (2001). Personality and performance and the beginning of the new millennium: What do we know and where do we go next? International Journal of Selection and Assessment, 9, 9-30.

Bar-On, R. (1997). Bar-On emotional quotient inventory: Technical manual. Toronto, Multihealth Systems.

Baron, R.M., \& Kenny, D.A. (1986). The moderator-mediator distinction in social psychological research: Conceptual, strategic, and statistical considerations. Journal of Personality and Social Psychology, 51, 1173-1182.

Baron-Cohen, S. (2002). The extreme male brain theory of autism. Trends in Cognitive Science, 6, 248-254.

Beal. D. J., Trougakos, J. P., Weiss, H. M., \& Green, S. G. (2006). Episodic processes in emotional labor: Perceptions of affective delivery and regulation strategies. Journal of Applied Psychology, 91, 1053-1065.

Beal, D. J., Weiss, H. M., Barros, E. \& MacDermid, S. M. (2005). An episodic process model of affective influences on performance. Journal of Applied Psychology, 90, 1054-1068.

Bedwell, S. (2003). Emotional Judgment Inventory (EJI): Administration and technical manual. Champaign, IL: Institute for Personality and Ability Testing, Inc..

Brody, L. R. (2000). The socialization of gender differences in emotional expression: Display rules, infant temperament, and differentiation. Gender and Emotion: Social Psychological Perspectives, 24-47. 
Brown, K. G., Le, H., \& Schmidt, F. L. (2006). Specific aptitude theory revisited: Is there incremental validity for training performance? International Journal of Selection and Assessment, 14, 87-100.

Carrothers, R. M., Gregory, S. W., \& Gallagher, T. J. (2000). Measuring emotional intelligence of medical school applicants. Academic Medicine, 75, 456-463.

Cattell, R. B. (1957). Personality and motivation structure and measurement. New York: World Book.

Cattell, R., \& Cattell, A. (1973). Measuring intelligence with the Culture Fair Tests: Manual for Scales 2 and 3. Champaign, IL: Institute for Personality and Ability Testing.

Ciarrochi, J., Chan, A. Y. C., \& Caputi, P. (2000). A critical evaluation of the emotional intelligence construct. Personality and Individual Differences, 28, 539-561.

College Entrance Examination Board and Educational Testing Service (1995).

Admission of Jicer's handbook for the W. T. program. Princeton, NJ: College Board SAT Program.

Conte, J. M., \& Dean, M. A. (2006). Can emotional intelligence be measured ? In K. R. Murphy (Ed.), A critique of emotional intelligence (pp. 59-78). Mahwah, NJ: Erlbaum.

Damasio, A. R. (1994). Descartes' error. New York: G. P. Putnam’s Sons.

Daus, C. S. (2006). The case for an ability-based model of emotional intelligence. In K. R. Murphy (Ed.), A critique of emotional intelligence (pp. 301-324). Mahwah, NJ: Erlbaum. 
Daus, C. S., \& Ashkanasy, N. M. (2003). Will the real emotional intelligence please stand up? On deconstructing the emotional intelligence "debate". The IndustrialOrganizational Psychologist, 41, 69-72.

Daus, C. S., \& Ashkanasy, N. M. (2005). The case for an ability-based model of emotional intelligence in organizational behavior. Journal of Organizational Behavior, 26, 453-466.

Day, A. L., \& Carroll, S. A. (2004). Using an ability-based measure of emotional intelligence to predict individual performance, group performance, and group citizenship behaviors. Personality and Individual Differences, 36, 1443-1458.

Equal Opportunity Employment Commission, Civil Service Commission, U.S.

Department of Labor, \& U.S. Department of Justice. (1978). Uniform guidelines on employee selection procedures. Federal Register, 43, 38290-38309.

Eysenck, H. J. (1970). The structure of human personality. London: University Press.

Eysenck, H. J. (1998). Intelligence: A new look. New Brunswick, NJ: Transaction Publishers.

Fiedler, K. (2000). Towards an integrative account of affect and cognition phenomena using the BIAS computer algorithm. In J. P. Forgas (Ed.), Feeling and thinking: The role of affect in social cognition (pp. 223-252). New York: Cambridge University Press.

Forgas, J. P. (1998). Happy and mistaken? Mood effects on the fundamental attribution error. Journal of Personality and Social Psychology, 75, 318-331. 
Forgas, J. P. (2002). Feeling and doing: Affective influences on interpersonal behavior. Psychological Inquiry, 13, 1-28.

Forgas, J. P., Ciarrochi, J. V., \& Moylan, S. J. (2000). Affective influences on the production of persuasive messages. Unpublished manuscript, University of New South Wales, Sydney, Australia.

Freudenthaler, H. H., \& Neubauer, A. C. (2005). Emotional intelligence: The convergent and discriminant validities of intra- and interpersonal emotional abilities. Personality and Individual Differences, 39, 569-579.

George, J. (2000). Emotions and leadership: The role of emotional intelligence. Human Relations, 53, 1027-1055.

Ghiselli, E. E., Campbell, J. P., \& Zedeck, S. (1981). Measurement Theory for the Behavioral Sciences. New York: W. H. Freeman and Co.

Gignac, G. E. (2005). Evaluating the MSCEIT V2.0 via CFA: Comment on Mayer et al. (2003). Emotion, 5, 233-235.

Goleman, D. (1995). Emotional intelligence: Why it can matter more than IQ. New York: Bantam Books.

Grandey, A. (2003). When 'the show must go on': Surface and deep acting as determinants of emotional exhaustion and peer-rated service delivery. Academy of Management Journal, 46 (1), 86-96.

Gross, J. J. (1998). The emerging field of emotion regulation: An integrative review. Review of General Psychology, 2, 271-299.

Heim, A. (1968). Manual of the AHS. Windsor: NFER. 
Holbrook, W. L. (1997). A study of the relationships between emotional intelligence and basic writers' skills. Unpublished doctoral dissertation, Ball State University, Muncie, IN.

Horn, J. L. (1975). Psychometric studies of aging and intelligence. In S. Gershon \& A. Kankin (Eds.), Aging, Volume 2: Genesis and treatment of psychological disorders in the elderly (pp. 450-474). New York: Raven Press.

Hough, L. M., Oswald, F. L., \& Ployhart, R. E. (2001). Determinants, detections and amelioration of adverse impact in personnel selection procedures: Issues, evidence and lessons learned. International Journal of Selection and Assessment, 9, 152-194.

Hu, L., \& Bentler, P. M. (1999). Cutoff criteria for fit indexes in covariance structure analysis: Conventional criteria versus new alternatives. Structural Equation Modeling, 6, 1-55.

Humphreys, L. G. (1979). The construct of general intelligence. Intelligence, 3(2), 105120.

Humphreys, L. G. (1984). General intelligence. In C. R. Reynolds \& R. T. Brown (Eds.), Perspectives on bias in mental testing (pp. 221-247). New York: Plenum Press.

Hunter, J. E., \& Hunter, R. F. (1984). Validity and utility of alternative predictors of job performance. Psychological Bulletin, 96, 72-98.

Hunter, J. E., \& Schmidt, F. L. (2004). Methods of meta-analysis. Thousand Oaks: Sage Publications. 
James, L. R., \& Brett, J. M. (1984). Mediators, moderators, and test for mediation. Journal of Applied Psychology, 69, 307-321.

James, L. R., Mulaik, S. A., \& Brett, J. M. (2006). A tale of two methods. Organizational Research Methods, 9, 233-244.

Jensen, A. R. (1980). Bias in mental testing. New York: Free Press.

Jordan, P. J., Ashkanasy, N. M., Hartel, C. E. J., \& Hooper, G. (2002). Workgroup emotional intelligence: Scale development and relationship to team process effectiveness and goal focus. Human Resource Management Review, 12, 195214.

Jöreskog, K., \& Sörbom, D. (2006). LISREL 8.80 Student Edition. Chicago, IL: Scientific Software International.

Judge, T. A., Erez, A., Bono, J. E., \& Thoresen, C. J. (2003). The core self-evaluations scale: Development of measure. Personnel Psychology, 56, 303-331.

Judge, T. A., Jackson, C. L., Shaw, J. C., Scott, B. A., \& Rich, B. L. (2007). Selfefficacy and work-related performance: The integral role of individual differences. Journal of Applied Psychology, 92, 107-127.

Judge, T. A., Thoresen, C. J., Bono, J. E., \& Patton, G. K. (2001). The job satisfactionjob performance relationship: A qualitative and quantitative review. Psychological Bulletin, 127, 376-407.

Keltner, D., Gruenfeld, D., \& Anderson, C. (2003). Power, approach, and inhibition. Psychological Review, 110, 265-284. 
Landy, F. J. (2005). Some historical and scientific issues related to research on emotional intelligence. Journal of Organizational Behavior, 26, 411-424.

Larsen, R. J. (2000). Toward a science of mood regulation. Psychological Inquiry, 11, $129-141$.

Locke, E. A. (2005). Why emotional intelligence is an invalid concept. Journal of Organizational Behavior, 26, 425-431.

Lynn, R. \& Irwing, P. (2004). Sex differences on the progressive matrices: A metaanalysis. Intelligence, 32, 481-498.

Matthews, G., Emo, A. K., Roberts, R. D., \& Zeidner, M. (2006). What is this thing called emotional intelligence? In K. R. Murphy (Ed.), A critique of emotional intelligence (pp. 3-36). Mahwah, NJ: Erlbaum.

Matthews, G., Zeidner, M., \& Roberts, R. D. (2002). Emotional intelligence: Science and myth. Cambridge, MA: MIT Press.

Mayer, J. D. (1999). Emotional intelligence: popular or scientific psychology? APA Monitor, 30, 50.

Mayer, J. D., Caruso, D. R., \& Salovey, P. (1999). Emotional intelligence meets traditional standards for emotional intelligence. Intelligence, 27, 267-298.

Mayer, J. D., \& Geher, G. (1996). Emotional intelligence and the identification of emotion. Intelligence, 22, 89-113.

Mayer, J. D., \& Salovey, P. (1997). What is emotional intelligence? In P. Salovey \& D. Sluyter (Eds.), Emotional development and emotional intelligence: Implications for educators (pp. 3-34). New York: Basic Books. 
Mayer, J. D., Salovey, P., \& Caruso, D. R. (2000). Models of emotional intelligence. In R. J. Sternberg (Ed.), Handbook of intelligence (pp. 392-420). Cambridge, England: Cambridge University Press.

Mayer, J. D., Salovey, P., Caruso, D. R., \& Sitarenios, G. (2003).Modeling and measuring emotional intelligence with the MSCEIT V2.0. Emotion, 3, 97-105.

McClure, E. B. (2000). A meta-analytic review of sex differences in facial expression processing and their development in infants, children, and adolescents. Psychological Bulletin, 126, 424-453.

McCrae, R. R., \& Costa, P. T. Jr. (1992). Discriminant validity of NOE-PIR facet scales. Educational and Psychological Measurement, 52, 229-237.

McIntosh, P. (1990). White privilege: Unpacking the invisible knapsack. Independent School, Winter, 31-36.

Mehrabian, A. (2001). Manual for the General Emotional Intelligence Scale (GEIS). (Available from Albert Mehrabian, 1130 Alta Mesa Road, Monterey, CA, 93940).

Murphy, K. R. (2006). Four conclusions about emotional intelligence. In K. R. Murphy (Ed.), A critique of emotional intelligence (pp. 345-354). Mahwah, NJ: Erlbaum.

Naglieri, J. A., \& Bardos, A. N. (1997). GAMA (general ability measure for adults): Manual. Minneapolis: National Computer Systems.

Newman, D. A., Jacobs, R. R., \& Bartram, D. (2007). Choosing the best method for local validity estimation: Relative accuracy of meta-analysis vs. a local study vs. Bayes analysis. Journal of Applied Psychology, 92, 1394-1413. 
Norman, W. T. (1963). Toward an adequate taxonomy of personality attributes: replicated factor structure in peer nomination personality ratings. Journal of Abnormal Social Psychology, 66, 574-583.

Nunnally, J. C. (1978). Psychometric theory. McGraw-Hill: New York.

Ones, D. S. (1993). The construct validity of integrity tests. Unpublished doctoral dissertation, The University of Iowa, Ames.

Owren, M. J., Rendall, D., \& Bachorowski, J. (2005). Conscious and unconscious emotion in nonlinguistic vocal communication. In L. F. Barrett, P. M. Niedenthal, \& P. Winkielman (Eds.), Emotion and Consciousness (pp. 185-204). New York: The Guilford Press.

Palmer, B. R., Gignac, G., Manocha, R., \& Stough, C. (2005). A psychometric evaluation of the Mayer-Salovey-Caruso Emotional Intelligence Test Version 2.0. Intelligence, 33, 285-305.

Palmer, B. R., \& Stough, C. (2001). Swinburne University Emotional Intelligence Test: Interim technical manual. Melbourne: Organisational Psychology Research Unit, Swinburne University of Technology (unpublished).

Paulhus, D. L. (1984). Two-component models of socially desirable responding. Journal of Personality and Social Psychology, 46, 598-609.

Petrides, K. V., \& Furnham, A. (2001). Trait emotional intelligence: Psychometric investigation with reference to established trait taxonomies. European Journal of Personality, 15, 425-448. 
Petrides, K. V., \& Furnham, A. (2003). Trait emotional intelligence: Behavioural validation in two studies of emotion recognition and reactivity to mood induction. European Journal of Personality, 17, 39-57.

Philiips, R., \& Rawles, R. (1979). S \& M Test of Mental Rotation Ability. Department of Psychology, University College, London.

Raven, J. C. (2003). Raven's progressive matrices. San Antonio, TX: The Psychological Corporation.

Raad, B. D. (2005). The trait-coverage of emotional intelligence. Personality and Individual Differences, 38, 673-687.

Rossen, E., Kranzler, J. H., \& Algina, J. (2008). Confirmatory factor analysis of the Mayer-Salovey-Caruso Emotional Intelligence Test V 2.0 (MSCEIT). Personality and Individual Differences, 44, 1258-1269.

Roth, P. L., BeVier, C., Bobko, P., Switzer, F., \& Tyler, P. (2001). Ethnic group differences in cognitive ability in employment and educational settings: A metaanalysis. Personnel Psychology, 54, 297-330.

Roth, P. L., Huffcutt, A. I., \& Bobko, P. (2003). Ethnic group differences in measures of job performance: A new meta-analysis. Journal of Applied Psychology, 88, 694706.

Roth, P. L, \& Purvis, K. L. (2007, August). A meta-analysis of standardized gender group differences of job performance in field studies. Paper presented at the Academy of Management Meetings in Philadelphia, PA. 
Sackett, P. R., \& Yang, H. (2000). Correction for range restriction: An expanded typology. Journal of Applied Psychology, 85, 112-118.

Sala, F. (2002). Emotional Competence Inventory: Technical manual. Hay Group, McClelland Center for Research and Innovation. Retrieved March 31, 2003, from http://www.eiconsortium.org/research/ECI_Tech_Manual.pdf.

Salovey, P., \& Grewal, D. (2005). The science of emotional intelligence. Current Directions in Psychological Science, 14, 281-285.

Salovey, P., \& Mayer, J. D. (1990). Emotional intelligence. Imagination, Cognition, and Personality, 9, 185-211.

Salovey, P., Mayer, J. D., Goldman, S., Turvey, C., \& Palfai, T. (1995). Emotional attention, clarity, and repair: Exploring emotional intelligence using the Trait Meta-Mood Scale. In J. W. Pennebaker (Ed.), Emotion, disclosure, and health (pp. 125-154). Washington, DC: American Psychological Association.

Schmidt, E. L., \& Hunter, J. E. (2004). General mental ability in the world of work: Occupational attainment and job performance. Journal of Personality and Social Psychology, 86, 162-173.

Schmidt, E. L., Hunter, J. E., \& Raju, N. S. (1988). Validity generalization and situational specificity: A second look at the 75\% rule and Fisher's z transformation. Journal of Applied Psychology, 73, 665-672.

Schmit, M. J. (2006). EI in the business world. In K. R. Murphy (Ed.), A critique of emotional intelligence (pp. 211-234). Mahwah, NJ: Erlbaum. 
Schulte, M. J., Ree, M. J., \& Carretta, T. R. (2004). Emotional intelligence: Not much more than $\mathrm{g}$ and personality. Personality and Individual Differences, 37, 10591068.

Schutte, N. S., Malouff, J. M., Hall, L. E., Haggerty, D. J., Cooper, J. T., Golden, C. J., \& Dornheim, L. (1998). Development and validation of a measure of emotional intelligence. Personality and Individual Differences, 25, 167-177.

Seo, M. G., Barrett, L. F., \& Bartunek, J. M. (2004). The role of affective experience in work motivation. The Academy of Management Review, 29, 423-439.

Shadish, W. R. (1996). Meta-analysis and the exploration of causal mediating processes: A primer of examples, methods, and issues. Psychological Methods, 1, 154-169.

Sinclair, R. C. (1988). Mood, categorization breadth, and performance appraisal: The effects of order of information acquisition and affective state on halo, accuracy, information retrieval, and evaluations. Organization Behavior and Human Decision Processes, 42, 22-46.

Sinclair, R. C. \& Mark, M. M (1992). The influence of mood state on judgment and action: Effects on persuasion, categorization, social justice, person perception, and judgmental accuracy. In L. L. Martin and A. Tesser (Eds.), The construction of social judgments (pp. 165-193). Hillsdale, NJ: Erlbaum.

Sjoberg, L. (2001a). Emotional intelligence: A psychometric analysis. European Psychologist, 6, 79-95. 
Snow, R. E., Kyllonen, P. C., \& Marshalek, B. (1984). The topography of ability and learning correlations. In R. J. Sternberg (Ed.), Advances in the psychology of human intelligence (Vol. 2, pp. 47-103). Hillsdale, NJ: Erlbaum.

Spearman, C. (1904). "General intelligence:" Objectively determined and measured. American Journal of Psychology, 15, 201-292.

Spector, P. E., \& Johnson, H. A. M. (2006). Improving the definition, measurement, and application of emotional intelligence. In K. R. Murphy (Ed.), A Critique of emotional intelligence (pp. 325-344). Mahwah, NJ: Lawrence Erlbaum Associates.

Stankov, L. (1997). Gf-Gc quickie test battery. Sydney, Australia: School of Psychology.

Sternberg, R. J. (1993). The Sternberg Triarchic Abilities Test (Level H). Unpublished test.

Sternberg, R. J. (2002). Foreword. In G. Matthews, A. Zeidner, \& R. Roberts (Eds.), Emotional intelligence: Science and myth (pp. xi-xiii). Cambridge, MA: The MIT Press.

Sternberg, R. J., Grigorenko, E. L., \& Kidd, K. K. (2005). Intelligence, Race, and Genetics. American Psychologist, 60, 46-59.

Tamir, M. (2005). Don’t worry, be happy? Neuroticism, trait-consistent affect regulation, and performance. Journal of Personality and Social Psychology, 89, 449-461. 
Tett, R. P., Fox, K. E., \& Wang, A. (2005). Development and validation of a self-report measure of emotional intelligence as a multidimensional trait domain. Personality and Social Psychology Bulletin, 31, 859-888.

Uchiyama, K., Shimai, T., Utsugi, N., \& Otake, K. (2001). EQS manual. Tokyo: Jitsumu-Kyoiku Syuppan. [in Japanese].

Underwood, M., Coie, J., \& Herbsman, C. (1992). Display rules for anger and aggression in school-age children. Child Development, 63, 366-380.

United States Department of Defense. (1984). Test Manual for the Armed Services Vocational Aptitude Battery (DoD No. 1340.12AA). North Chicago, IL: U.S. Military Entrance Processing Command.

United States Department of Labor (1970). General Aptitude Test Battery: Section III. Development. Washington, DC: U.S. Government Printing Office.

Van Rooy, D. L., Alonso, A., \& Viswesvaran, C. (2005). Group differences in emotional intelligence scores: Theoretical and practical implications. Personality and Individual Differences, 38, 689-700.

Van Rooy, D. L., \& Viswesvaran, C. (2004). Emotional intelligence: A meta-analytic investigation of predictive validity and nomological net. Journal of Vocational Behavior, 65, 71-95.

Van Rooy, D. L., Viswesvaran, C., \& Pluta, P. (2005). An evaluation of construct validity: What is this thing called Emotional Intelligence? Human Performance, $18,445-462$. 
Viswesvaran, C., \& Ones, D. S. (1995). Theory testing: Combining psychometric metaanalysis with structural equation modeling. Personnel Psychology, 48, 865-885.

Viswesvaran, C. \& Ones, D. S. (2000). Measurement error in "big five factors"

personality assessment: Reliability generalization across studies and measures. Educational and Psychological Measurement, 60, 224-235.

Viswesvaran, C., Ones, D. S., \& Schmidt, F. L. (1996). Comparative analysis of the reliability of job performance ratings. Journal of Applied Psychology, 81, 557574.

Watson, D., \& Clark. A. C. (1992). On traits and temperament: General and specific factors of emotional experience and their relation to the Five-Factor Model. Journal of Personality, 60, 441-476.

Watson, G. B., \& Glaser, E. M. (1994). Watson-Glaser Critical Thinking Appraisal Manual-Form S. San Antonio, TX: The Psychological Corportation.

Wechsler, D. (1955). Wechsler adult intelligence scale. San Antonio, TX: The Psychological Corporation.

Wechsler, D. (1999). Wechsler abbreviated scale of intelligence. San Antonio, TX: The Psychological Corporation.

Western Psychological Services (1967). Shipley Institute of Living Scale. Los Angeles.

Whitener, E. M. (1990). Confusion of confidence intervals and credibility intervals in meta-analysis. Journal of Applied Psychology, 75, 315-321.

Wonderlic. (2000). The wonderlic personnel test. Libertyville, IL: Wonderlic, Inc. 
Wong, C., \& Law, D. S. (2002). The effects of leader and follower emotional intelligence on performance and attitude: An exploratory study. The Leadership Quarterly, 13, 243-274.

Yerkes, R. M. (1921). Psychological examining in the United States. Memoirs of the National Academy of Sciences (15: 890 pp. entire). Washington, D.C.: National Academy of Sciences.

Zeidner, M., Matthews, G., \& Roberts, R. D. (2004). Emotional intelligence in the workplace: A critical review. Applied Psychology: An International Review, 53, 371-399. 


\section{APPENDIX}

\section{REFERENCE LIST OF STUDIES INCLUDED IN THE CURRENT META-}

\section{ANALYSIS}

Alfolabi, O. A., \& Ehigie, B. O. (2005). Psychological diversity and team interaction processes: A study of oil-drilling work teams in Nigeria. Team Performance Management, 11, 280-301.

Amelang, M., \& Steinmayr, R. (2006). Is there a validity increment for tests of emotional intelligence in explaining the variance of performance criteria? Intelligence, 34, 459-468.

Austin, E. J., Farrelly, D., Black, C., \& Moore, H. (2007). Emotional intelligence, Machiavellianism, and emotional manipulation: Does EI have a dark side? Personality and Individual Differences, 43, 179-189.

Austin, E. J., Saklofske, D. H., \& Egan, V. (2005). Personality, well-being and healthcorrelates of trait emotional intelligence. Personality and Individual Differences, $38,547-558$.

Barchard, K. A. (2001). Emotional and social intelligence: Examining its place in the nomological network. Unpublished Doctoral Dissertation, The University of British Columbia, Vancouver, Canada.

Barchard, K. A., \& Hakstian, A. R. (2004). The nature and measurement of emotional intelligence abilities: Basic dimensions and their relationships with other cognitive ability and personality variables. Educational and Psychological Measurement, 64, 437-462. 
Bastian, V. A., Burns, N. R., \& Nettlebeck, T. (2005). Emotional intelligence predicts life skills, but not as well as personality and cognitive abilities. Personality and Individual Differences, 39, 1135-1145.

Beshears, R. S. (2004). The ability of emotional intelligence to predict transformational leadership when personality, affect, and cognitive ability are controlled. Unpublished Doctoral Dissertation, Wayne State University, Detroit, MI.

Boncher, M. K. (2003). The relationship between attachment styles and emotional intelligence. Unpublished doctoral dissertation, New York University.

Boyce, D. A. (2001). The correlation of emotional intelligence, academic success, and cognitive ability in master's level physical therapy students. Unpublished doctoral dissertation, Spalding University, Louisville, KY.

Brackett, M. A., \& Mayer, J. D. (2003). Convergent, discriminant, and incremental validity of competing measures of emotional intelligence. Personality and Social Psychology Bulletin, 29, 1147-1158.

Brackett, M. A., Mayer, J. D., \& Warner, R. M. (2004). Emotional intelligence and its relation to everyday behavior. Personality and Individual Differences, 36, 13871402.

Brackett, M. A., Rivers, S. E., Shiffman, S., Lerner, N., \& Salovey, P. (2006). Relating emotional abilities to social functioning: A comparison of self-report and performance measures of emotional intelligence. Journal of Personality and Social Psychology, 91, 780-795. 
Bryant, D. (2005). The components of emotional intelligence and the relationship to sales performance. Unpublished doctoral dissertation, George Washington University, Washington, DC.

Byrne, J. C., Dominick, P. G., Smither, J. W., \& Reilly, R. R. (2007). Examination of the discriminant, convergent, and criterion-related validity of self-ratings on the Emotional Competence Inventory. International Journal of Selection and Assessment, 15, 341-353.

Carmeli, A., \& Josman, Z. E. (2006). The relationship among emotional intelligence, task performance, and organizational citizenship behaviors. Human Performance, 19, 403-419.

Carrothers, R. M., Gregory, S. W., \& Gallagher, T. J. (2000). Measuring emotional intelligence of medical school applicants. Academic Medicine, 75, 456-463.

Cavins, B. J. (2005). The relationship between emotional-social intelligence and leadership practices among college student leaders. Unpublished doctoral dissertation, Bowling Green State University, Bowling Green, OH.

Chamorro-Premuzic, T., Bennett, E., \& Furnham, A. (2007). The happy personality: Mediational role of trait emotional intelligence. Personality and Individual Differences, 42, 1633-1639.

Chapman, B. P. (2005). Emotional intelligence at mid life: A cross sectional investigation of structural variance, social correlates, and relationship to established personality and ability taxonomies. Unpublished Doctoral Dissertation, University of North Texas, Denton. 
Ciarrochi, J., Chan, A. Y. C., \& Caputi, P. (2000). A critical evaluation of the emotional intelligence construct. Personality and Individual Differences, 28, 539-561.

Click, H. S. (2002). An exploration of emotional intelligence scores among students in educational administration endorsement programs. Unpublished doctoral dissertation, East Tennessee State University, Johnson City.

Cote, S., \& Miners, C. T. H. (2006). Emotional intelligence, cognitive intelligence, and job performance. Administrative Science Quarterly, 51, 1-28.

Davies, M. D., Stankov, L., \& Roberts, R. D. (1998). Emotional intelligence: In search of an elusive construct. Journal of Personality and Social Psychology, 75, 9891015.

Dawda, D., \& Hart, S. D. (2000). Assessing emotional intelligence: Reliability and validity of the Bar-On Emotional Quotient Inventory (EQ-i) in university students. Personality and Individual Differences, 28, 797-812.

Day, A. L., \& Carroll, S. A. (2004). Using an ability-based measure of emotional intelligence to predict individual performance, group performance, and group citizenship behaviors. Personality and Individual Differences, 36, 1443-1458.

Day, A. L., Therrien, D. L., \& Carroll, S. A. (2005). Predicting psychological health: Assessing the incremental validity of emotional intelligence beyond personality, type A behaviour and daily hassles. European Journal of Personality, 19, 519536. 
Derksen, J., Kramer, I., \& Katzo, M. (2002). Does a self-report measure for emotional intelligence assess something different than general intelligence? Personality and Individual Differences, 32, 37-48.

Douglas, C., Frink, D. D., \& Ferris, G. R. (2003). Emotional intelligence as a moderator of the relationship between conscientiousness and performance. Journal of Leadership and Organizational Studies, 10, 2-13.

Dulewicz, V., Higgs, M., \& Slaski, M. (2003). Measuring emotional intelligence: Content, construct and criterion-related validity. Journal of Managerial Psychology, 5, 405-420.

Dunn, E. W., Brackett, M. A., Ashton-James, C., Schneiderman, E., \& Salovey, P. (2007). On emotionally intelligent time travel: Individual differences in affective forecasting ability. Personality and Social Psychology Bulletin, 33, 85-93.

Extremera, N., Fernandez-Berrocal, P. (2005). Perceived emotional intelligence and life satisfaction: Predictive and incremental validity using the Trait Meta-Mood Scale. Personality and Individual Differences, 39, 937-948.

Farrelly, D., \& Austin, E. J. (2007). Ability EI as an intelligence? Associations of the MSCEIT with performance on emotion processing and social tasks and with cognitive ability. Cognition and Emotion, 21, 1043-1063.

Fillion, F. (2001). The construct validation of two measures of emotional intelligence. Unpublished master's thesis, University of Guelph, Ontario, Canada. 
Fox, S., \& Spector, P. E. (2000). Relations of emotional intelligence, practical intelligence, general intelligence, and trait affectivity with interview outcomes: It's not all just 'G'. Journal of Organizational Behavior, 21, 203-220.

Freudenthaler, H. H., \& Neubauer, A. C. (2005). Emotional intelligence: The convergent and discriminant validities of intra- and interpersonal emotional abilities. Personality and Individual Differences, 39, 569-579.

Fukunishi, I., Wise, T. N., Sheridan, M., Shimai, S., Orake, K., Utsuki, N., \& Uchiyama, K. (2001). Validity and reliability of the Japanese version of the emotional intelligence scale among college students and psychiatric outpatients. Psychological Reports, 89, 625-632.

Furnham, A. (2005). Self-estimated intelligence, psychometric intelligence and personality. Psychologia, 48, 182-192.

Gannon, N., \& Ranzijn, R. (2005). Does emotional intelligence predict unique variance and life satisfaction beyond IQ and personality? Personality and Individual Differences, 38, 1353-1364.

Graves, J. G. (1999). Emotional intelligence and cognitive ability: Predicting performance in job-simulated activities. Unpublished doctoral dissertation, California School of Professional Psychology.

Grubb, W. L., \& McDaniel, M. A. (2007). The fakability of Bar-On's Emotional Quotient Inventory Short Form: Catch me if you can. Human Performance, 20, 43-59. 
Hader, E. M. (2006). Emotional intelligence and its relationship to cognitive and social task requirements. Unpublished doctoral dissertation, Alliant International University.

Hong, Y. (2005). Motivation to lead: Antecedents resulting in leader emergence. Unpublished Doctoral Dissertation, Saint Mary's University.

Ivcevic, Z., Brackett, M. A., \& Mayer, J. D. (2007). Emotional intelligence and emotional creativity. Journal of Personality, 75, 199-236.

Janovics, J., \& Christiansen, N. D. (2002). Emotional intelligence in the workplace. Paper presented at the $16^{\text {th }}$ Annual Conference of the Society of Industrial and Organizational Psychology, San Diego, CA.

Johnson, H. M., \& Spector, P. E. (2007). Service with a smile: Do emotional intelligence, gender, and autonomy moderate the emotional labor process? Journal of Occupational Health Psychology, 12, 319-333.

King, D. H. (1999). Measurement of differences in emotional intelligence of preservice educational leadership students and practicing administrators as measured by the Multifactor Emotional Intelligence Scale. Unpublished Doctoral Dissertation, East Carolina University, Greenville, NC.

Kluemper, D. H. (2006). An examination of ability-based emotional intelligence in the structured employment interview. Unpublished doctoral dissertation, Oklahoma State University, Stillwater. 
Kohan, A. (2002). Emotional intelligence: An investigation of discriminant and concurrent validity. Unpublished doctoral dissertation, Lakehead University, Thunder Bay, Ontario, Canada.

Kostman, J. T. (2004). Multi-dimensional performance requires multi-dimensional predictors: Predicting complex job performance using cognitive ability, personality, and emotional intelligence assessment instruments as combinatorial predictors. Unpublished doctoral dissertation, The City University of New York.

Lam, L. T. (1998). Emotional intelligence: Implications for individual performance. Unpublished doctoral dissertation, Texas Tech University, Lubbock.

Lam, L. T., \& Kirby, S. L. (2002). Is emotional intelligence an advantage? An exploration of the impact of emotional and general intelligence on individual performance. The Journal of Social Psychology, 142, 133-143.

Law, K. S., Wong, C., \& Song, L. J. (2004). The construct and criterion validity of emotional intelligence and its potential utility for management studies. Journal of Applied Psychology, 89, 483-496.

Lindley, L. D. (2001). Personality, other dispositional variables, and human adaptability. Unpublished doctoral dissertation, Iowa State University, Ames.

Livingstone, H. A., \& Day, A. L. (2005). Comparing the construct and criterion-related validity of ability-based and mixed-model measures of emotional intelligence. Educational and Psychological Measurement, 65, 757-779.

Lopes, P. N. (2004). Emotional abilities and the quality of interpersonal interaction. Unpublished doctoral dissertation, Yale University, New Haven, CT. 
Lopes, P. N., Brackett, M. A., Nezlek, J., Schutz, A., Sellin, I., \& Salovey, P. (2004). Emotional intelligence and social interaction. Personality and Social Psychology Bulletin, 30, 1018-1034.

Lopes, P. N., Grewal, D., Kadis, J., Gall, M., \& Salovey, P. (2006). Evidence that emotional intelligence is related to job performance and affect and attitudes at work. Psicothema, 18, 132-138.

Lopes, P. N., Salovey, P., \& Straus, R. (2003). Emotional intelligence, personality and the perceived quality of social relationships. Personality and Individual Differences, 35, 641-658.

MacCann, C., Roberts, R. D., Matthews, G., \& Zeidner, M. (2004). Consensus scoring and empirical option weighting of performance-based emotional intelligence (EI) tests. Personality and Individual Differences, 36, 645-662.

Mack-Allen, J. (2001). Relationship between emotional intelligence and personality factors in a community-based sample. Unpublished doctoral dissertation, Widener University, Chester, PA.

Martinez-Pons, M. (1997-98). The relation of emotional intelligence with selected areas of personal functioning. Imagination, Cognition, and Personality, 17, 3-13.

Matthews, G., Emo, A. K., Funke, G. Zeidner, M., Roberts, R. D., Costa, P. T., \& Schulze, R. (2006). Emotional intelligence, personality, and task-induced stress. Journal of Experimental Psychology: Applied, 12, 96-107.

Mayer, J. D., Caruso, D. R., \& Salovey, P. (1999). Emotional intelligence meets traditional standards for emotional intelligence. Intelligence, 27, 267-298. 
Mestre, J. M., Guil, R., Lopes, P. N., Salovey, P., \& Gil-Olarte, P. (2006). Psicothema, $16,112-117$.

Moss, M., Ritossa, D., \& Ngu, D. (2006). The effect of follower regulatory focus and extraversion on leadership behavior: The role of emotional intelligence. Journal of Individual Differences, 27, 93-107.

Murensky, C. L. (2000). The relationship between emotional intelligence, personality, critical thinking ability, and organizational leadership performance at upper levels of management. Unpublished doctoral dissertation, George Mason University, Fairfax, VA.

Newsome, S., Day, A. L., \& Catano, V. M. (2000). Assessing the predictive validity of emotional intelligence. Personality and Individual Differences, 29, 1005-1016.

O'Connor, R. M., Jr., \& Little, I. S. (2003). Revisiting the predictive validity of emotional intelligence: Self-report versus ability-based measures. Personality and Individual Differences, 35, 1893-1902.

Pasanen, S. E. (2000). Emotional intelligence, conscientiousness and integrity as predictors of organizational citizenship behavior. Unpublished master's thesis, University of California, Los Angeles.

Pellitteri, J. (2002). The relationship between emotional intelligence and ego defense mechanisms. The Journal of Psychology, 136, 182-194.

Petrides, K. V., \& Furnham, A. (2001). Trait emotional intelligence: Psychometric investigation with reference to established trait taxonomies. European Journal of Personality, 15, 425-448. 
Petrides, K. V., \& Furnham, A. (2006). The role of trait emotional intelligence in a gender-specific model of organizational variables. Journal of Applied Social Psychology, 36, 552-569.

Petrides, K. V., Niven, L., Mouskounti, T. (2006). The trait emotional intelligence of ballet dancers and musicians. Psicothema, 18, 101-107.

Petrides, K. V., Pita, R., \& Kokkinaki, F. (2007). The location of trait emotional intelligence in personality factor space. British Journal of Psychology, 98, 273289.

Rego, A., Sousa, G., Cunha, M. P., Correia, A., \& Sair-Amaral, I. (2007). Leader selfreported emotional intelligence and perceived employee creativity: An exploratory study. Creativity and Innovation Management, 16, 250-264.

Roberts, R. D., Zeidner, M., \& Matthews, G. (2001). Does emotional intelligence meet traditional standards for an intelligence? Some new data and conclusions. Emotion, 1, 196-231.

Rode, J. C., Mooney, C. H., Arthaud-Day, M. L., Near, J. P., Baldwin, T. T., Rubin, R. S., \& Bommer, W. H. (2007). Emotional intelligence and individual performance: Evidence of direct and moderated effects. Journal of Organizational Behavior, 28, 399-421.

Rosete, D., \& Ciarrochi, J. (2005). Emotional intelligence and its relationship to workplace performance outcomes of leadership effectiveness. Leadership and Organization Development Journal, 26, 388-399. 
Rovnak, A. (2007). A psychometric investigation of the Emotional Quotient Inventory in adolescents: A construct validation and estimate of stability. Unpublished doctoral dissertation, The University of Akron, Akron, $\mathrm{OH}$.

Saklofske, D. H., Austin, E. J., Galloway, J., \& Davidson, K. (2007). Individual difference correlates of health-related behaviors: Preliminary evidence for links between emotional intelligence and coping. Personality and Individual Differences, 42, 491-502.

Saklofske, D. H., Austin, E. J., \& Minski, P. S. (2003). Factor structure and validity of trait emotional intelligence measure. Personality and Individual Differences, 34, 707-721.

Schmidt, L. L. (2006). Self-reported emotional intelligence as an indicator of social exchange quality at work. Unpublished doctoral dissertation, University of Houston, TX.

Schulte, M. J., Ree, M. J., \& Carretta, T. R. (2004). Emotional intelligence: Not much more than $g$ and personality. Personality and Individual Differences, 37, 10591068.

Schumacher, L. A. (2005). The relationship between supply managers' emotional intelligence and their performance. Unpublished doctoral dissertation, Bowling Green State University, OH.

Schutte, N. S., Malouff, J. M., Hall, L. E., Haggerty, D. J., Cooper, J. T., Golden, C. J., \& Dornheim, L. (1998). Development and validation of a measure of emotional intelligence. Personality and Individual Differences, 25, 167-177. 
Semadar, A., Robins, G., \& Ferris, G. R. (2006). Comparing the validity of multiple social effectiveness constructs in the prediction of managerial job performance. Journal of Organizational Behavior, 27, 443-461.

Shaikh, A. (2004). Emotional intelligence: Is it intelligence or a personality trait? Unpublished Doctoral Dissertation, Laurentian University, Sudbury, Ontario, Canada.

Shi, J., \& Wang, L. (2007). Validation of emotional intelligence scale in Chinese university students. Personality and Individual Differences, 43, 377-387.

Sjoberg, L. (2001a). Emotional intelligence: A psychometric analysis. European Psychologist, 6, 79-95.

Sjoberg, L. (2001b). Emotional intelligence measured in a highly competitive testing situation. Unpublished manuscript, Center for Economic Psychology, Stockhold School of Economics, Sweden.

Smith, J. E. (2000). Emotional intelligence and behavior: An exploratory study of people on parole. Unpublished doctoral dissertation, Kansas State University, Manhattan.

Stewart, J. H. (1997). Practical intelligence: Assessing its convergent and discriminant validity with social, emotional, and academic intelligence. Unpublished doctoral dissertation, University of Southern Mississippi, Hattiesburg.

Sue-Chan, C., \& Latham, G. P. (2004). The situational interview as a predictor of academic and team performance: A study of the mediating effects of cognitive 
ability and emotional intelligence. International Journal of Selection and Assessment, 12, 312-320.

Sy, T., Tram. S., \& O’Hara, L. A. (2006). Relation of employee and manager emotional intelligence to job satisfaction and performance. Journal of Vocational Behavior, $68,461-473$.

Tett, R. P., Fox, K. E., \& Wang, A. (2005). Development and validation of a self-report measure of emotional intelligence as a multidimensional trait domain. Personality and Social Psychology Bulletin, 31, 859-888.

Thomas, M.D. (2005). Response biases and the five-factor personality construct. Unpublished master's thesis, Mississippi State University.

Thompson, B. L., Waltz, J., Croyle, K., \& Pepper, A. C. (2007). Trait meta-mood and affect as predictors of somatic symptoms and life satisfaction. Personality and Individual Differences, 43, 1786 - 1795.

Tombs, S. (2004). Challenging the bell curve: An assessment of the role of emotional intelligence in career placement and performance. Unpublished Doctoral Dissertation, York University, Toronto, Ontario, Canada.

Van Rooy, D. L., Alonso, A., \& Viswesvaran, C. (2005). Group differences in emotional intelligence scores: Theoretical and practical implications. Personality and Individual Differences, 38, 689-700.

Vela, R. H., Jr. (2003). The role of emotional intelligence in the academic achievement of first year college students. Unpublished doctoral dissertation, Texas A\&M University at Kingsville. 
Walker, M. E. B. (2006). Emotional intelligence and academic success in college. Unpublished doctoral dissertation, The University of Southern Mississippi, Hattiesburg.

Warwick, J., \& Nettelbeck, T. (2004). Emotional intelligence is...? Personality and Individual Differences, 37, 1091-1100.

Wolfradt, U., Felfe, J., \& Koster, T. (2001-2002). Self-perceived emotional intelligence and creative personality. Imagination, Cognition and Personality, 21, 293-309.

Wong, C., Foo, M., Wang, C., \& Wong, P. (2007). The feasibility of training and development of EI: An exploratory study in Singapore, Hong Kong and Taiwan. Intelligence, 35, 141-150.

Wong, C., \& Law, D. S. (2002). The effects of leader and follower emotional intelligence on performance and attitude: An exploratory study. The Leadership Quarterly, 13, 243-274.

Wraight, M. E. (2006). The impact of trait emotional intelligence and cognitive style on the academic achievement and life satisfaction of college students. Unpublished doctoral dissertation, The State University of New York at Buffalo. 


\section{VITA}

Name:

Address:

Email Address:

Education:
Dana Lanay Rhodes

Dept. of Psychology

Texas A\&M University

4235 TAMU

College Station, TX 77843-4235

drhodes@psych.tamu.edu

dlrhodes@gmail.com

B.A. in Psychology and Biology, The University of Southern California, 2006

M.S. in Industrial and Organizational Psychology, Texas A\&M

University, 2008 